\title{
Morphological changes of glutamatergic synapses in animal models of Parkinson's disease
}

\author{
Rosa M. Villalba ${ }^{1,2 *}$, Abraham Mathai ${ }^{1,2}$ and Yoland Smith ${ }^{1,2,3}$ \\ ${ }^{1}$ Yerkes National Primate Research Center, Emory University, Atlanta, GA, USA, ${ }^{2}$ UDALL Center of Excellence for \\ Parkinson's Disease, Emory University, Atlanta, GA, USA, ${ }^{3}$ Department of Neurology, Emory University, Atlanta, GA, USA
}

\section{OPEN ACCESS}

Edited by:

Javier Blesa,

Centro Integral de Neurociencias (CINAC), Spain

Reviewed by:

Gordon William Arbuthnott, Okinawa Institute of Science and Technology, Japan Rachel Jane Sizemore, University of Otago, New Zealand (in collaboration with Louise Parr-Brownlie) Louise Parr-Brownlie, University of Otago, New Zealand

*Correspondence: Rosa M. Villalba, Yerkes National Primate Research Center, Emory University, 954 Gatewood Road NE, Atlanta, GA 30329, USA rvillal@emory.edu

Received: 22 June 2015 Accepted: 17 August 2015 Published: 25 September 2015

Citation: Villalba RM, Mathai $A$ and Smith Y (2015) Morphological changes of glutamatergic synapses in animal models of Parkinson's disease.

Front. Neuroanat. 9:117. doi: 10.3389/fnana.2015.00117
The striatum and the subthalamic nucleus (STN) are the main entry doors for extrinsic inputs to reach the basal ganglia (BG) circuitry. The cerebral cortex, thalamus and brainstem are the key sources of glutamatergic inputs to these nuclei. There is anatomical, functional and neurochemical evidence that glutamatergic neurotransmission is altered in the striatum and STN of animal models of Parkinson's disease $(\mathrm{PD})$ and that these changes may contribute to aberrant network neuronal activity in the BG-thalamocortical circuitry. Postmortem studies of animal models and PD patients have revealed significant pathology of glutamatergic synapses, dendritic spines and microcircuits in the striatum of parkinsonians. More recent findings have also demonstrated a significant breakdown of the glutamatergic corticosubthalamic system in parkinsonian monkeys. In this review, we will discuss evidence for synaptic glutamatergic dysfunction and pathology of cortical and thalamic inputs to the striatum and STN in models of PD. The potential functional implication of these alterations on synaptic integration, processing and transmission of extrinsic information through the BG circuits will be considered. Finally, the significance of these pathological changes in the pathophysiology of motor and non-motor symptoms in PD will be examined.

Keywords: Parkinson's disease, striatum, subthalamic nucleus, synaptic plasticity, glutamatergic synapses, vGluT, astrocytes plasticity

\section{Basal Ganglia Nuclei and Connectivity}

The basal ganglia (BG) are a collection of interconnected subcortical nuclei, including the striatum, globus pallidus (GP), substantia nigra, and subthalamic nucleus (STN), which closely interact with the cerebral cortex and thalamus. While historically considered as key components of the motor system, the BG receive cortical projections from all functional areas of the cerebral cortex and contribute to both motor and non-motor functions (Alexander et al., 1986; Mink, 1996). The information flow through the BG circuitry is segregated into motor, associative, and limbic/emotional domains based on their relationships with specific cortical projection areas and the engagement of these regions in various behaviors (Alexander et al., 1986; Lanciego et al., 2012). A large number of findings discussed in this review were gathered from the motor-related nuclei of the primate BG. The striatum, the major input structure of the BG, receives projections from the cerebral cortex, brainstem, and thalamus. The GP consists of two anatomically and functionally separate nuclei, the external and internal pallidal segments [GPe and GPi, respectively in primates; GP and entopeduncular nucleus (EPN) in rodents]. The substantia nigra also comprises two separate nuclei, the 
GABAergic pars reticulata ( $\mathrm{SNr}$ ) and the pars compacta ( $\mathrm{SNc}$ ), which contains pigmented dopamine (DA)-containing neurons. The dopaminergic neurons of the SNc project primarily to the striatum, but also provide significant innervation of other BG nuclei and the thalamus (particularly in primates; Smith and Kieval, 2000; García-Cabezas et al., 2009; Rommelfanger and Wichmann, 2010). The glutamatergic STN is a small nucleus which is intercalated between GPe and GPi. In addition to the striatum, the STN is also considered as a major entry for cortical information to the BG network (Nambu et al., 2000; DeLong and Wichmann, 2010), while the GPi (or EPN in non-primates) and $\mathrm{SNr}$ are the two main output nuclei of the BG.

The striatum and the STN receive topographically organized projections from functionally diverse regions of the cerebral cortex (Parent and Hazrati, 1995; Nambu et al., 1996). Because information flows more rapidly to the BG output nuclei via the corticosubthalamic projection than via the direct and indirect trans-striatal pathways, the trans-subthalamic route is commonly referred to as the "hyperdirect" pathway of the BG (Nambu et al., 2000, 2002; Sano et al., 2013; Smith and Wichmann, 2015). While the corticosubthalamic projection is less extensive than the corticostriatal system, it originates from motor, associative and limbic cortical regions and is a powerful source of excitation to STN neurons through which cortical inputs can rapidly regulate the activity of downstream BG output nuclei, the GPi and SNr (Monakow et al., 1978; Nambu et al., 2000; Haynes and Haber, 2013). Corticosubthalamic axons target dendritic spines and distal dendritic shafts of STN neurons in rats (Bevan et al., 1995; Mathai et al., 2015).

The GPe is another key structure of the BG which receives its main inputs from the striatum (the so-called indirect pathway) and the STN. In turn, two different populations of GPe neurons provide GABAergic innervation to all other BG nuclei. The so-called "arkypallidal" cells are the main sources of the pallidostriatal system, while the "prototypic" cells project massively to the STN, with collateral to the GPi and SNr (Shink et al., 1996; Smith et al., 1998a,b; Mallet et al., 2012; Dodson et al., 2015). There is recent evidence for a direct GABAergic/cholinergic pallidocortical projection in mouse (Saunders et al., 2015).

The BG outflow is directed at specific thalamic and brainstem nuclei via the GPi and $\mathrm{SNr}$, largely through collateralized axonal projections (Parent and De Bellefeuille, 1982; Parent et al., 1983). The BG-receiving ventral motor thalamic nuclei project to widespread areas of the frontal lobe and send projections back to the striatum, while descending projections from the BG to the brainstem terminate massively in the pedunculopontine nucleus (PPN) which, in turn, provide significant ascending and descending projections to the thalamus, BG, reticular formation and spinal cord (Rye et al., 1988; Lavoie and Parent, 1994; Parent and Hazrati, 1995; Mena-Segovia et al., 2004). Recent evidence indicates that the descending transPPN projections may play an important role in regulating brainstem and spinal motor mechanisms related to gait and balance (Pahapill and Lozano, 2000; Garcia-Rill et al., 2011). The PPN is also part of several feedback circuits with projections to the BG and the thalamus (Rye et al., 1988; Lavoie and
Parent, 1994; Mena-Segovia et al., 2004). Other projections from the $\mathrm{SNr}$ reach the superior colliculus, which is involved in coordinating head and eye movements, while a specific subset of peripallidal GPi neurons project massively to the lateral habenula, and play a role in the modulation of reward and limbic mechanisms (Wurtz and Hikosaka, 1986; Wickens, 2008; Hikosaka, 2010).

Recent studies suggest the existence of a direct glutamatergic cortico-pallidal projection in mammals, including humans (Mathai et al., 2012; Smith et al., 2014c; Milardi et al., 2015; Smith and Wichmann, 2015). This "cortico-pallidal" system is separate from the descending cortico-spinal and cortico-pontine axons that travel through the internal capsule (Naito and Kita, 1994; Milardi et al., 2015; Smith and Wichmann, 2015), and bypasses the traditional direct, indirect, and hyperdirect corticofugal pathways. The existence of this direct glutamatergic cortico-pallidal projection could have a significant impact on our present understanding of transmission and processing of information through the BG circuits in normal and diseased states (Smith and Wichmann, 2015).

\section{The Striatum: Main Entry to the BG Circuitry}

The dorsal striatum, made up of the putamen and caudate nucleus in primates, is mainly innervated by sensorimotor (postcommissural putamen) and associative (caudate nucleus and precommissural putamen) cortices, respectively, while the ventral striatum (nucleus accumbens and olfactory tubercle) is the main target of limbic-related inputs from the hippocampus, amygdala and medial prefrontal cortices (Russchen et al., 1985; Alexander et al., 1986; McGeorge and Faull, 1987; Haber et al., 1995; Parent and Hazrati, 1995; Fudge et al., 2002). In the human literature the term "lenticular" or "lentiform" nucleus is commonly used to refer to the putamen and the GP (Carpenter and Sutin, 1983).

Each striatal region also receives prominent functionallyrelated thalamic inputs from intralaminar, relay, associative and midline nuclei. Among those, the caudal intralaminar nuclear group, the centre median (CM) and parafascicular complex $(\mathrm{Pf})$, which innervates preferentially the putamen or caudate nucleus, respectively (Smith et al., 2004, 2009a; Galvan and Smith, 2011) is the predominant source of thalamostriatal projections. Massive dopaminergic innervation from either the SNc (to the dorsal striatum) or the ventral tegmental area (VTA; to the ventral striatum) provides key modulatory influences upon striatal processing of extrinsic cortical and thalamic information (Smith and Bolam, 1990; Nicola et al., 2000; Gerfen and Surmeier, 2011). Additional extrinsic inputs from the hypothalamus, GP, STN, raphe, locus coeruleus and PPN have also been described (Smith and Parent, 1986; Parent and Hazrati, 1995; Smith et al., 1998a,b; Ellender et al., 2011).

\section{Striatal Projection Neurons and Interneurons}

The main targets of extrinsic inputs to the striatum are the GABAergic medium spiny neurons (MSNs), which represent 
90-97\% of all striatal neurons (Kemp and Powell, 1971a,b,c; Oorschot, 1996; Wickens et al., 2007a). These GABAergic neurons can be categorized into two main populations based on their hodological and chemical phenotypes. The "direct" pathway neurons send their main axonal projections directly to the output nuclei of the BG (i.e., GPi and SNr), and express preferentially the D1 DA receptors (D1R) and the neuropeptides substance P (SP) and dynorphin (DYN). On the other hand, the "indirect" pathway neurons project preferentially to the GPe, and express D2 receptors (D2R) and the neuropeptide enkephalin (ENK; Gerfen et al., 1990; Sidibé and Smith, 1999; Lanciego et al., 2004; Lei et al., 2004, 2013; Smith et al., 2009a, 2014a,b,c; Galvan and Smith, 2011; Gerfen and Surmeier, 2011; HuertaOcampo et al., 2014). Albeit less frequent, it is noteworthy that some striatal MSNs project to both GPe and GPi/SNr and coexpress D1 and D2 DA receptor subtypes (Kawaguchi et al., 1990; Surmeier and Kitai, 1993; Surmeier et al., 1996; Wu et al., 2000).

The dendritic trees of both populations of striatal MSNs are covered with spines, which are the main targets of glutamatergic inputs from the cerebral cortex and thalamus. In rodents, the dendrites of individual MSNs harbor as many as 5000 spines (Wickens et al., 2007a). In addition to their glutamatergic innervation, striatal spines also receive synaptic inputs from midbrain dopaminergic neurons which frequently terminate onto the neck of the spine or a nearby segment of the dendritic shaft, thereby providing an anatomical substrate for close synaptic interactions between glutamatergic and dopaminergic inputs at the level of spines (Freund et al., 1984; Smith and Bolam, 1990; Smith et al., 1994, 2009a, 2014a; Nicola et al., 2000; Wickens et al., 2007a; Moss and Bolam, 2008). These functional interactions are critical for the development and maintenance of long-term synaptic plasticity of glutamatergic corticostriatal synapses (Nicola et al., 2000; Calabresi et al., 2007; Surmeier et al., 2007, 2010; Gerfen and Surmeier, 2011; Picconi et al., 2012). Although D1R and D2R MSNs display very similar morphological characteristics, the D2R MSNs exhibit increased excitability and harbor a less extensive dendritic tree than D1R cells in mice (Gertler et al., 2008; Kreitzer and Malenka, 2008; Fieblinger et al., 2014b), and each type of MSNs is differentially modulated by DA in normal and diseased states (Surmeier et al., 2007; Day et al., 2008; Kreitzer and Malenka, 2008; Shen et al., 2008; Kreitzer, 2009; Fieblinger et al., 2014b).

The aspiny interneurons are far fewer in number, accounting for about $3-10 \%$ of the total striatal population (Tepper and Bolam, 2004; Bernácer et al., 2005, 2007, 2012). Anatomically, they can be categorized into medium-sized GABAergic cells and large cholinergic neurons (Kawaguchi et al., 1995; Bernácer et al., 2007, 2012; Gonzales and Smith, 2015). Mediumsized GABAergic interneurons can be further classified histochemically into different subtypes: (a) parvalbuminpositive; (b) somatostatin-, neuropeptide $\mathrm{Y}$-, and nitric oxide synthase-positive; (c) calretinin-positive (Tepper and Bolam, 2004; Bernácer et al., 2005, 2007, 2012); and (d) tyrosine hydroxylase (TH)-positive (Tepper et al., 2010). It is noteworthy that the latter subtype is rare in the normal primate striatum, but undergoes an upregulation after striatal DA denervation (Betarbet et al., 1997; Mazloom and Smith, 2006; Bernácer et al., 2012). It remains unclear if the various subtypes of TH-positive GABAergic cells described in TH-Cre mice (Tepper et al., 2010) represent the same neuronal phenotype as those seen in 1-methyl-4-phenyl-1,2,3,6-tetrahydropyridine (MPTP)-treated monkeys and Parkinson's disease (PD) patients.

\section{DA Mesostriatal System}

DA plays a fundamental role in normal BG function. The mesostriatal dopaminergic system, which comprises the mesolimbic and the nigrostriatal pathways, enables BG control of motor planning and action selection (Wurtz and Hikosaka, 1986; Berns and Sejnowski, 1998; Gurney et al., 2001). Because of its involvement in a wide array of physiologic and pathologic processes, the anatomical and functional organization of the DA mesostriatal systems has been the topic of extensive studies for many years (for reviews, see Wickens et al., 2007b,c; Kreitzer, 2009; Gerfen and Surmeier, 2011). Despite such interest, the exact role of DA in normal BG function is complex and remains poorly understood. The whole striatum is densely innervated by dopaminergic axons and terminals (Lavoie et al., 1989; Prensa and Parent, 2001; Matsuda et al., 2009; Bolam and Pissadaki, 2012; Pissadaki and Bolam, 2013) that originates from the ventral midbrain including the SNc (A9), VTA (A10) and retrorubral Area (RRA; A8). The A9 group is the most densely packed group of midbrain dopaminergic cells located in the SNc. Projections from SNc and RRA neurons terminate in the dorsal striatum, while VTA neurons are the main source of DA innervation to the ventral striatum (Gerfen et al., 1987; Lynd-Balta and Haber, 1994a,b). Dopaminergic terminal boutons represent nearly $10 \%$ of all striatal terminals (Groves et al., 1994). Like other monoamines, there is evidence that DA can mediate its effects in striatal and extrastriatal brain regions through neurotransmitter diffusion (Arbuthnott et al., 2000; Cragg and Rice, 2004; Arbuthnott and Wickens, 2007; Wickens et al., 2007b; Descarries et al., 2008; Moss and Bolam, 2008; Rice and Cragg, 2008; Rice et al., 2011). Consistent with this hypothesis, most DA receptors in the striatum are located extrasynaptically in spines and dendrites of striatal neurons (Hersch et al., 1995; Yung et al., 1995; Delle Donne et al., 1996, 1997; Nicola et al., 2000; Wang and Pickel, 2002; Gerfen and Surmeier, 2011).

\section{GABA and Glutamate: Co-transmitters of the Nigrostriatal System}

Recent evidence indicates that DA neurons in the $\mathrm{SNc}$ and VTA are capable of co-releasing GABA with DA, and inhibit striatal projection neurons (Tritsch et al., 2012, 2014). It is estimated that $5-10 \%$ of SNc DA neurons express GAD65 and fewer than $1 \%$ contain the vesicular glutamate transporter 2 (vGluT2) in rodents (González-Hernández et al., 2001; BérubéCarrière et al., 2009; Hnasko et al., 2010). Therefore, distinct subpopulations of DA neurons may release GABA or glutamate, 
and reliable detection of IPSCs and EPSCs may result from innervation of SPNs by several DA neurons (Matsuda et al., 2009). Future studies are needed to better understand the physiological (or pathological) conditions under which GABA, glutamate and DA are released or co-released from nigrostriatal axons.

The release of GABA from DA terminals is independent of vesicular GABA transporter (vGAT), but requires activity of the vesicular monoamine transporter 2 (vMAT2) for vesicular loading. The inhibitory GABAergic synaptic transmission from DA neurons does not depend on synthesis of GABA by either GADs (GAD65, GAD67) or GABA transaminase, suggesting that DA neurons inhibit MSNs by releasing GABA they acquire from the extracellular space using membrane uptake of GABA (Tritsch et al., 2014). Although the actions of DA are not believed to be spatially localized (Arbuthnott and Wickens, 2007), this corelease of GABA may confer dopaminergic neurons an additional point-to-point mode of action, and the flexibility to differentially control GABAergic transmission in a target-dependent manner across their extensive axonal arbors (Tritsch et al., 2014). It is noteworthy that evidence for GABA expression and release from other populations of monoaminergic neurons has been reported in other brain regions (Iijima, 1993; Trottier et al., 2002; Maher and Westbrook, 2008; Hirasawa et al., 2009; Broadbelt et al., 2010). Together, these findings expand the repertoire of synaptic mechanisms available to monoaminergic cells, and suggest that perturbations of GABA co-transmission might contribute to the etiology of monoaminergic pathologies or to the therapeutic efficacy of vMAT2 antagonists in specific brain disorders.

There is also evidence that a certain contingent of $\mathrm{SNc}$ and VTA DA neurons can store and release glutamate via the vGluT2, providing an additional level of chemical heterogeneity to the nigrostriatal system (Sulzer et al., 1998; Chuhma et al., 2004; Bérubé-Carrière et al., 2009; Yamaguchi et al., 2013; Antal et al., 2014; Morales and Root, 2014; Trudeau et al., 2014). The localization of metabotropic glutamate receptor 5 at the edges of striatal dopaminergic synapses in the monkey striatum (Paquet and Smith, 2003) is consistent with these observations.

\section{Striatal DA Receptor Subtypes}

In addition to the strong and segregated expression of D1R and $\mathrm{D} 2 \mathrm{R}$ in direct and indirect pathway MSNs, both GABAergic and cholinergic interneurons also express different subtypes of DA receptors, and their activity is tightly regulated by DA, most particularly that of cholinergic interneurons, which express both D2R and D5R (Yan and Surmeier, 1997; Yan et al., 1997; Day et al., 2006; Wang et al., 2006; Surmeier et al., 2007; Kreitzer, 2009; Gerfen and Surmeier, 2011). D3R and D4R are also expressed in both the dorsal and ventral striata (Landwehrmeyer et al., 1993; Rivera et al., 2002; Centonze et al., 2003). DA receptors are expressed to variable degree in other BG nuclei, providing a substrate for extrastriatal DA functions (Smith and Kieval, 2000; Rommelfanger and Wichmann, 2010). In addition to their post-synaptic localization, DA receptors are localized pre-synaptically in glutamatergic and GABAergic terminals throughout the BG circuitry, providing multiple targets through which DA regulatory influences can impact neurotransmission in normal and diseased states. The readers are referred to comprehensive reviews of the topic for additional information (Arbuthnott et al., 2000; Reynolds and Wickens, 2002; Costa, 2007; Rice and Cragg, 2008; Surmeier et al., 2010; Gerfen and Surmeier, 2011; Rice et al., 2011).

\section{Glutamatergic Synaptic Plasticity in PD and its Models}

\section{Striatal Spine Loss in PD}

Striatal spine loss has been reported in the striatum of various animal models of PD and in parkinsonian patients. In both MPTP-treated monkeys and PD patients, the extent of spine pruning is tightly correlated with the extent of striatal dopaminergic denervation (Ingham et al., 1989; Stephens et al., 2005; Zaja-Milatovic et al., 2005; Smith and Villalba, 2008; Smith et al., 2009b; Villalba et al., 2009; Toy et al., 2014; Figures 1A,B, 4).

\section{Striatal Spine Loss on Direct vs. Indirect Striatofugal Neurons}

Although there has been some controversy as to whether the striatal spine loss targets preferentially direct (D1Rpositive) vs. indirect (D2R-positive) striatal MSNs, recent evidence indicates that both neuronal subtypes are affected, but through different mechanisms. Some authors reported that D2R striatopallidal neurons, but not D1R striatonigral neurons, selectively lose spines in reserpine-(systemic administration) and 6-hydroxydopamine (OHDA)-treated (injection in the medial forebrain bundle) mice with striatal DA depletion (Day et al., 2006). However, other reports described spine loss on both direct and indirect pathway neurons in intrastriatal 6-OHDA-treated or systemically MPTP-treated mice (Suárez et al., 2014; Toy et al., 2014). Similarly, both populations of striatal projection neurons undergo significant spine loss in monkeys chronically treated with low doses of MPTP (Villalba et al., 2009; Villalba and Smith, 2010, 2013). These findings are consistent with the homogeneous loss of spines across large populations of striatal MSNs described in Golgi studies of human parkinsonians and animal models of parkinsonism (Ingham et al., 1989; Stephens et al., 2005; Zaja-Milatovic et al., 2005; Smith and Villalba, 2008; Smith et al., 2009b; Villalba et al., 2009; Villalba and Smith, 2010, 2013). However, other monkey studies, using an acute regimen of MPTP toxicity, suggested a decrease in $\mathrm{D} 2 \mathrm{R}$ spines accompanied with an increase in the density of D1R spines in the caudate nucleus of MPTP-treated cynomolgus monkeys (Scholz et al., 2008). The use of different animal models, different regimens and locations of neurotoxin administration, variable quantitative methods and observations of different striatal regions may contribute to these discrepancies.

In addition to spine pruning, recent evidence showed that the length and complexity of the dendritic tree of both direct and indirect pathway MSNs are significantly reduced in 

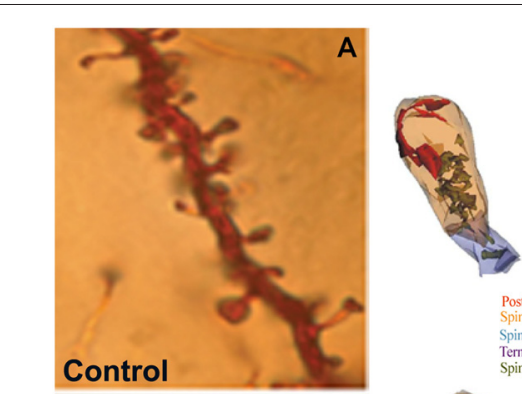

C1

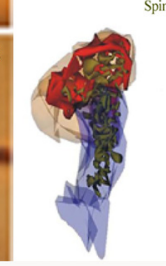

D1

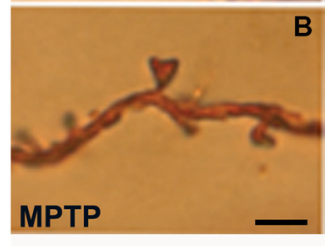

D1
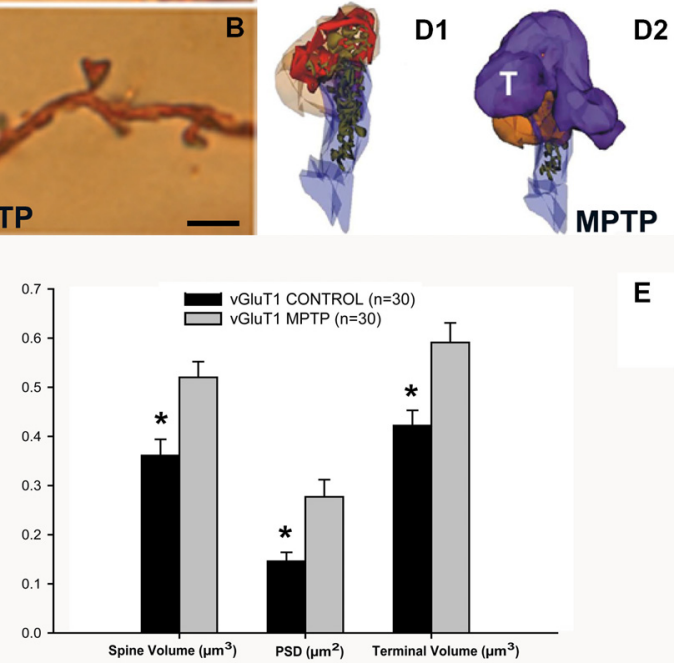

E

FIGURE 1 | Dendritic spines in the monkey striatum. (A,B) Light micrographs of dendrites from Golgi-impregnated medium spiny neurons (MSNs) in the caudate nucleus of a control (A) and a

1-methyl-4-phenyl-1,2,3,6-tetrahydropyridine (MPTP)-treated (B) monkey. Note the dramatic spine loss of the dendrite of the MSN from the MPTP-treated monkey compared with control. (C1-D2) Three-dimension (3D)-reconstructed images of glutamatergic axo-spinous synapses from control (C1,C2) and MPTP-treated (D1,D2) monkeys. (E) Histogram comparing the morphometric measurements (mean \pm SEM) for spine volume $\left(\mu \mathrm{m}^{3}\right)$, post-synaptic density (PSD) area $\left(\mu \mathrm{m}^{2}\right)$ and terminal volume $\left(\mu \mathrm{m}^{3}\right)$ of structural elements at corticostriatal (vGluT1-positive) glutamatergic synapses using $3 \mathrm{D}$ reconstruction method of serial ultrathin sections collected from 30 axo-spinous synapses in each group from three control and three MPTP-treated animals. The spine volumes, the PSD areas, and the volume of vGluT1-containing terminals are significantly larger in MPTP-treated parkinsonian monkeys than in controls ( ${ }^{*} t$-test; $\left.p<0.001\right)$. Scale bar in (B) (applied to A) $=5 \mu \mathrm{m}$ (See Villalba et al., 2009; Villalba and Smith, 2010, 2011a, 2013).

6-OHDA-treated mice (Fieblinger et al., 2014a). In contrast to spine loss, that responds to L-DOPA therapy in this animal model, dendritic arbor atrophy is unresponsive to DA replacement therapy (Fieblinger et al., 2014a).

\section{Does Striatal Spine Loss Affect Corticostriatal and Thalamostriatal Synapses?}

Using unbiased stereological synaptic counts, Ingham et al. (1998) reported $\sim 20 \%$ decrease in the total number of axospinous asymmetric synapses in the striatum of 6-OHDAtreated rats. Recent findings from our laboratory also show a significant decrease in the total number of putative glutamatergic
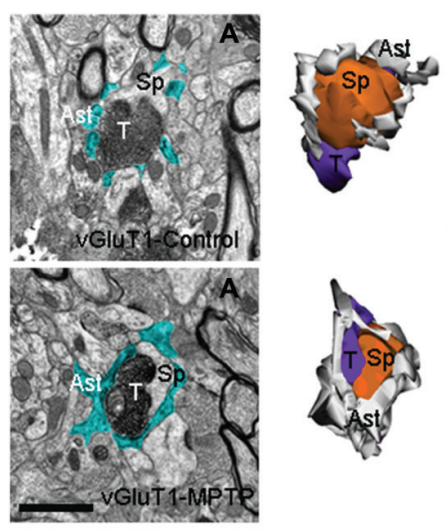

B

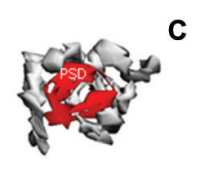

vGluT1- Control

E
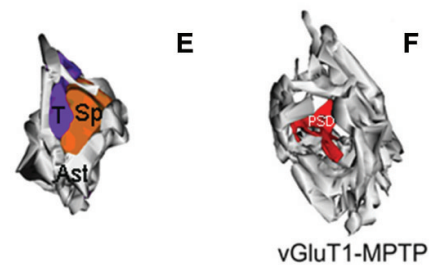

G
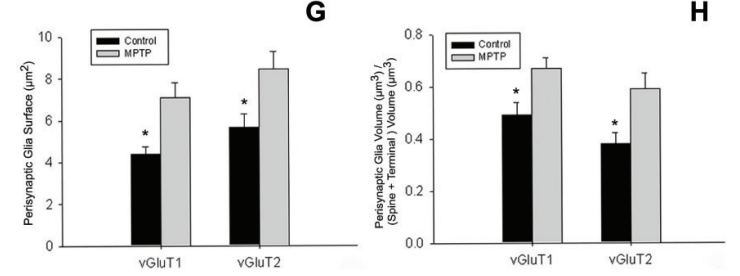

FIGURE 2 | Tripartite synapses (TS) in the monkey striatum. (A,D) Electron micrographs of perisynaptic astrocytic processes (Ast) wrapping a vGluT1 axo-spinous synapse in control (A) and MPTP-treated (D) animal. (B,C,E,F) The three-dimensional (3D) reconstruction of a vGluT1-immunoreactive TS highlight the differences in the extensions of the astrocytic processes between control $(\mathbf{B}, \mathbf{C})$ and MPTP $\mathbf{( E , F ) . ~ I n ~ t h e ~ T S ~ o f ~}$ control animals, the perimeters of the axon-spinous interfaces were only partially surrounded by astroglial processes $(\mathbf{B}, \mathbf{C})$. In MPTP-treated animals, TS vGluT1-containing synapses displayed a large increase in astroglial processes ensheatment (E,F). (G) Histograms comparing the surface area of perisynaptic glia associated with vGluT1- and vGluT2-immunopositive axo-spinous synapses in control $(N=3)$ and MPTP-treated $(N=3)$ monkeys (mean \pm SEM). The surface of the perisynaptic glia was significant larger $\left({ }^{*}\right.$, $t$-test, $p=0.017$ for vGluT1 and $p=0.006$ for vGluT2) in MPTP-parkinsonian monkeys than in control. (H) Histograms comparing the ratio of the volume of the perisynaptic glia over the total volume of spine and the axon terminals in TS formed by vGluT1- or vGluT2-immunoreactive terminals. This ratio was significantly larger in MPTP than in control condition $\left({ }^{*}, t\right.$-test, $p=0.049$ for vGluT1 and $p=0.028$ for vGluT2). No significant difference was found between TS formed by vGluT1- or vGluT2-immunoreactive terminals. Total number of reconstructed spines $=32$ (8 per group). Statistics were performed by using SigmaPlot (version 11.0). Abbreviations: Ast, astrocyte; PSD, post-synaptic density; Sp, dendritic spine; T, axon terminal (see Villalba and Smith, 2011b for details).

terminals (as revealed by asymmetric synaptic specializations) in the putamen of MPTP-treated parkinsonian monkeys (Villalba et al., 2013). To determine if this terminal loss is accounted for by a reduction in the number of cortical vs. thalamic boutons, antibodies raised against the vesicular glutamate transporter 1 (vGluT1) or vGluT2 were used as specific markers of corticostriatal or thalamostriatal terminals, respectively. Findings obtained in these studies remain controversial. On one hand, data from chronically MPTP-treated parkinsonian monkeys revealed that the relative density of vGluT1- or vGluT2positive terminals in the putamen and the caudate nucleus is either unchanged or significantly increased compared with controls (Raju et al., 2008). These findings are consistent with human data showing a slight increase in the amount 
of vGluT1 protein expression in the putamen of PD patients compared with controls (Kashani et al., 2007). However, data from unilateral 6-OHDA-treated rats or mice indicate a profound reduction in the number of vGluT1-positive terminals, without any significant alteration in vGluT2-postive thalamic boutons, in these animals (Zhang et al., 2013; Fieblinger et al., 2014a). Whether these discrepancies are due to differences in the toxin being used (6-OHDA vs. MPTP), or the chronic nature of the MPTP regimen administered in monkeys compared with the acute 6-OHDA-induced lesion of the nigrostriatal projection in rodents remains to be determined.

Anatomical and functional data indicate that the loss of spines induces various forms of structural and functional synaptic homeostatic adaptations in MSNs of parkinsonian animals. For instance, the various components of vGluT1and vGluT2-positive corticostriatal and thalamostriatal synapses undergo structural changes consistent with an increased synaptic strength, ie increase in the volume of the spines, increase in the size of the pre-synaptic terminals, increase in the area and complexity of the post-synaptic densities (PSD) and massive growth of the spine apparatus (Figures 1C-E), in the putamen of chronically MPTP-treated monkeys (Villalba and Smith, 2010, 2011a, 2013). Similar changes have been associated with intraspinous increase in protein synthesis and calcium buffering in other brain regions (Fifková et al., 1983; Bourne and Harris, 2008; Plotkin et al., 2013), thereby providing further evidence for increased corticostriatal glutamatergic transmission at these remaining synapses. However, this remains to be demonstrated using adequate electrophysiological approaches.

In a recent study, Fieblinger et al. (2014a) used glutamate uncaging approach at specific axo-spinous corticostriatal synapses, and found that the intrinsic excitability of direct pathway MSNs was increased, while that of indirect pathway neurons was decreased, in 6-OHDA-treated mice. On the other hand, the excitatory corticostriatal synaptic connectivity on indirect, but not direct, striatofugal neurons was lower in 6-OHDA-treated mice than controls. Finally, they also reported that in neither case was the strength of corticostriatal connections globally scaled (Fieblinger et al., 2014a). Together, these observations indicate that striatal MSNs undergo complex homeostatic (or pathologic) changes of glutamatergic synapses in response to striatal DA depletion that could affect differentially the direct and indirect striatofugal pathways in PD.

\section{Is the 6-OHDA-treated Rodent Model of PD Suitable to Study Striatal Spine Plasticity in PD?}

Together, these recent findings (Zhang et al., 2013; Fieblinger et al., 2014a; Suárez et al., 2014) and previous studies (Ingham et al., 1989, 1998; Meshul et al., 2000; Day et al., 2006; Deutch et al., 2007; Neely et al., 2007) highlight the complex nature of the plastic changes striatal MSNs undergo in the 6-OHDA-treated rodent model of PD. However, the translation of these findings to the parkinsonsian state in humans must be achieved with caution because of the differential pathology of striatal glutamatergic afferents between the models under study and PD patients. Most importantly, $\mathrm{PD}$ is characterized by a massive degeneration of $\mathrm{CM} / \mathrm{Pf}$ neurons (Henderson et al., 2000a,b; Smith et al., 2014a; Villalba et al., 2014), the main sources of the glutamatergic thalamostriatal system. The loss of these neurons and their corresponding axonal projections to the striatum is likely to further contribute to the synaptic homeostasis and scaling properties of remaining glutamatergic synapses in the PD striatum. Thus, the translation of morphological and functional studies of glutamatergic synapses in the striatum of PD models to the human parkinsonian condition must take into consideration the extent of CM/Pf degeneration (Villalba et al., 2013, 2014).

Although chronically MPTP-treated rhesus monkeys display 40-50\% neuronal loss in CM/Pf (Villalba et al., 2013, 2014), the extent of Pf neuronal loss reported in various rodent models of $\mathrm{PD}$ is variable. While some authors did not find evidence for Pf degeneration 3 months after unilateral 6-OHDA nigrostriatal dopaminergic lesion in rats (Henderson et al., 2005; Kusnoor et al., 2012), other studies reported significant Pf cell loss in the same animal model (Aymerich et al., 2006; Sedaghat et al., 2009), or after systemic MPTP administration in mice (Freyaldenhoven et al., 1997). Some authors also showed that intrastriatal administration of 1-methyl-4-phenylpyridinium ion $(\mathrm{MPP}+)$ induces significant Pf cells damage in rats (Ghorayeb et al., 2002a). It remains to be determined whether these discrepancies were the result of differences in the neurotoxin exposure protocols, animal strains or other technical differences between these studies.

The need of animal models that include degeneration of the thalamostriatal system from $\mathrm{CM} / \mathrm{Pf}$ is warranted for future studies of the plastic reorganization of striatal glutamatergic afferents in PD (Smith et al., 2014b; Villalba et al., 2014). Based on recent studies and others, it appears that MPTP toxicity might be a more reliable tool to induce $\mathrm{CM} / \mathrm{Pf}$ neuronal loss and degeneration of the thalamostriatal system in mice and monkeys (Ghorayeb et al., 2002b; Smith et al., 2014a,b; Toy et al., 2014; Villalba et al., 2014).

\section{L-DOPA-induced Dyskinesias (LID) and Striatal Spine Plasticity}

Although striatal spine loss has long been recognized in the striatum of DA-depleted animals and PD patients, the effects of DA replacement therapy on spine pruning, reorganization of synapic connectivity and homeostatic plasticity remains poorly understood. However, recent studies showed that LDOPA therapy partly restores some structural and functional aspects of corticostriatal connection in rodent models of PD (Zhang et al., 2013; Nishijima et al., 2014; Suárez et al., 2014; Fieblinger and Cenci, 2015). Some authors, indeed, reported that the loss of spines and vGluT1-positive terminals in the striatum of 6-OHDA-treated rats and mice could be reversed by chronic treatment with L-DOPA (Zhang et al., 2013; Suárez et al., 2014). However, in animals that developed LDOPA-induced dyskinesia (LID), the spines displayed abnormal synaptic relationships with vGluT1-positive terminals such 

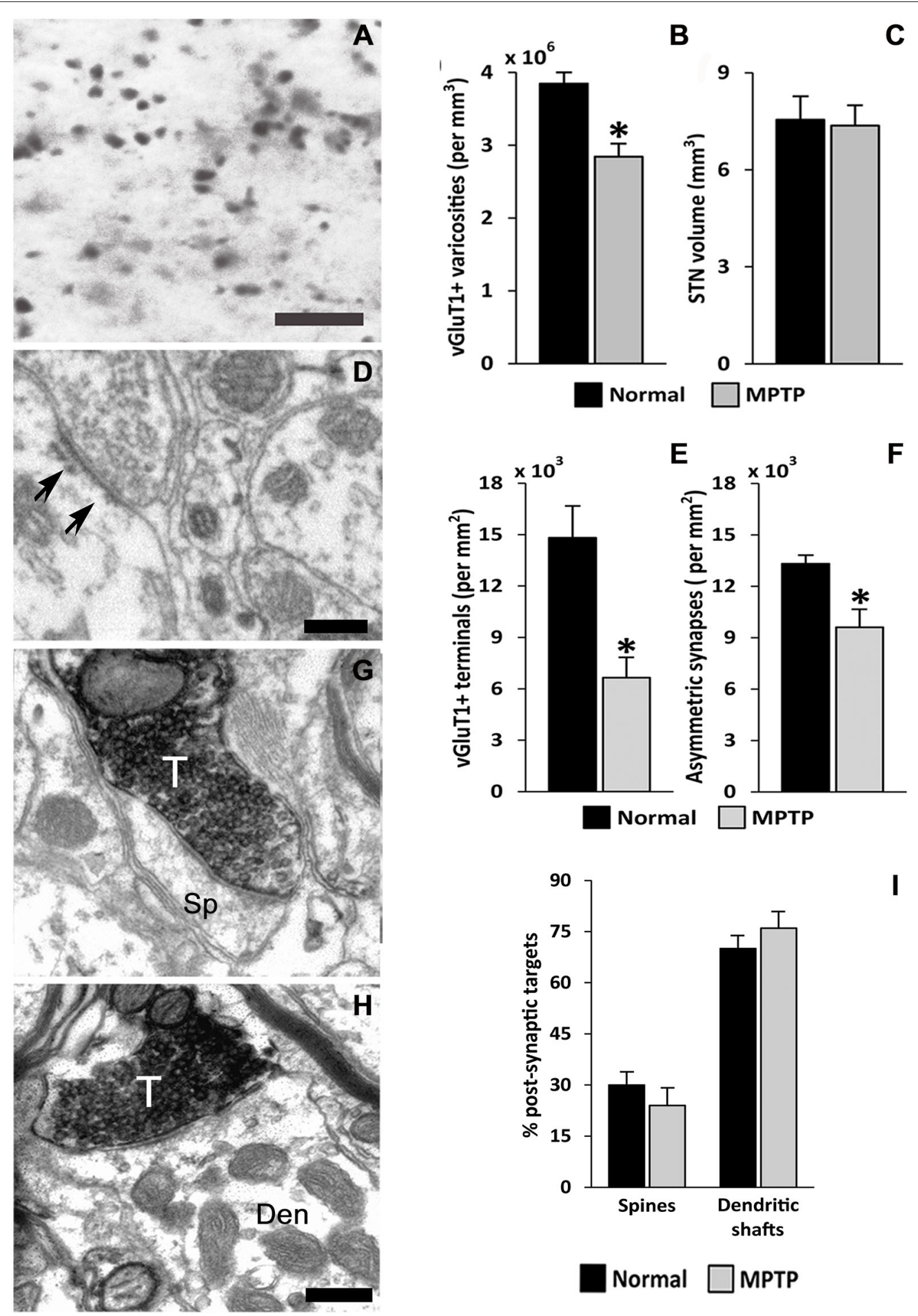

FIGURE 3 | vGluT1-positive innervation in the monkey subthalamic nucleus (STN). (A) Light micrograph showing vGluT1-positive varicose processes. (B) Average density (mean $\pm \mathrm{SEM} ; N=3$ ) of vGluT1-immunoreactive varicosities in the dorsolateral STN of normal and parkinsonian monkeys ( ${ }^{*}, t$-test, $p=0.012$ ). (C) Comparison of the average STN volume (mean $\pm \mathrm{SEM} ; N=3$ ) between normal and parkinsonian monkeys. (D) Electron micrograph showing an asymmetric synapse (arrows) in the dorsolateral monkey STN. (E) Average density (mean \pm SEM; $N=3$ ) of vGluT1-immunopositive terminals in the dorsolateral STN of normal and parkinsonian monkeys $\left({ }^{*}, t\right.$-test, $p=0.02$ ). (F) Average density (mean $\pm \mathrm{SEM} ; N=3$ ) of asymmetric synapses in the dorsolateral STN of normal and pakinsonian monkeys $\left({ }^{*}\right.$, $t$-test, $\left.p=0.029\right)$. (G,H) Electron micrographs showing vGluT1-containing terminals forming asymmetric synapses with a spine (G) and a dendritic shaft (H). (I) Post-synaptic targets of vGluT1-immunopositive terminals in the dorsolateral STN. No differences were found in the proportion of vGluT1-immunoreactive terminals forming asymmetric synapses with dendritic shafts and spines in normal and parkinsonian animals. Scale bar $\mathbf{A}=10 \mu \mathrm{m}$ and in (D; applies also to $\mathbf{G}$ ) and $\mathbf{H}=0.2 \mu \mathrm{m}$. Abbreviations: Den, dendrite; Sp, dendritic spine; T, axon terminal (See Mathai et al., 2015). 
that single spines often received synaptic inputs from 2 or more vGluT1-positive terminals (Zhang et al., 2013). Because this pathology was not found in non-dyskinetic L-DOPAtreated animals, the authors concluded that aberrant cortical innervation of striatal MSNs may be an important substrate of dysfunctional neuronal communication associated with LID (Zhang et al., 2013). Another main conclusion of this study was that neither the 6-OHDA lesion nor the L-DOPA treatment affected the prevalence and synaptic connections of vGluT2positive thalamostriatal terminals in this animal model (Zhang et al., 2013). These observations were recently confirmed and extended in a recent study, which showed that both direct and indirect pathway MSNs manifest complex, and opposite, changes in homeostatic plasticity that affect their average firing rate in PD and LID states (Fieblinger et al., 2014a). Results of this study further demonstrated that the only adaptation found to be exclusively associated with LID was the restoration of excitatory axo-spinous synapses on the surface of indirect pathway neurons (Fieblinger et al., 2014a; see also Suárez et al., 2014).

As discussed above, an important shortcoming of these studies is the lack of evidence for thalamostriatal degeneration in the animal models used in these studies. The use of animal models of PD with CM/Pf pathology is essential to relate the neuroplastic properties of striatal MSNs and their glutamatergic responses to the human PD state (Smith et al., 2014b).

\section{Cellular, Molecular and Genetic Mechanisms for Striatal Spine Loss in PD}

Although the mechanisms underlying striatal spine loss in PD remain unclear, there is converging evidence that intraspinous calcium $\left(\mathrm{Ca}^{2+}\right)$ dysregulation likely contributes to this pathology (Segal et al., 2000; Sabatini et al., 2001; Oertner and Matus, 2005; Day et al., 2006; Deutch et al., 2007; Surmeier et al., 2007, 2011; Chen et al., 2008; Soderstrom et al., 2010; Surmeier and Schumacker, 2013). The Cav1.3 $\alpha 1$ channels on D2R-containing neurons appear to be particularly important in mediating the spine pruning on indirect striatofugal neurons in mice (Day et al., 2006; Deutch et al., 2007; Surmeier et al., 2007; Soderstrom et al., 2010; Fieblinger et al., 2014b). In line with evidence that abnormal $\mathrm{Ca}^{2+}$ homeostasis may participate in this pathology, striatal MSNs devoid of the $\mathrm{Ca}^{2+}$ buffering protein, calbindin D-28k (CaB; Francois et al., 1994), such as those in the postcommissural putamen (sensorimotor striatal territory), display the most severe striatal spine pruning in parkinsonian monkeys (Smith and Villalba, 2008; Smith et al., 2009b; Villalba et al., 2009).

In vitro data suggest that the activation of the $\mathrm{Ca}^{2+}$-dependent protein phosphatase, calcineurin, and the up-regulation of the transcriptional activity of the myocyte enhancer factor 2 (MEF2) and related regulatory genes (Nurr77, Arc) participate in the loss of glutamatergic synapses and spines in the striatum (Pulipparacharuvil et al., 2008; Tian et al., 2010; Villalba and Smith, 2013). Evidence that cholinergic signaling through M1 muscarinic receptors and Kir2 potassium channels may trigger the loss of glutamatergic synapses in rodent models of parkinsonism has also been suggested (Shen et al., 2008).

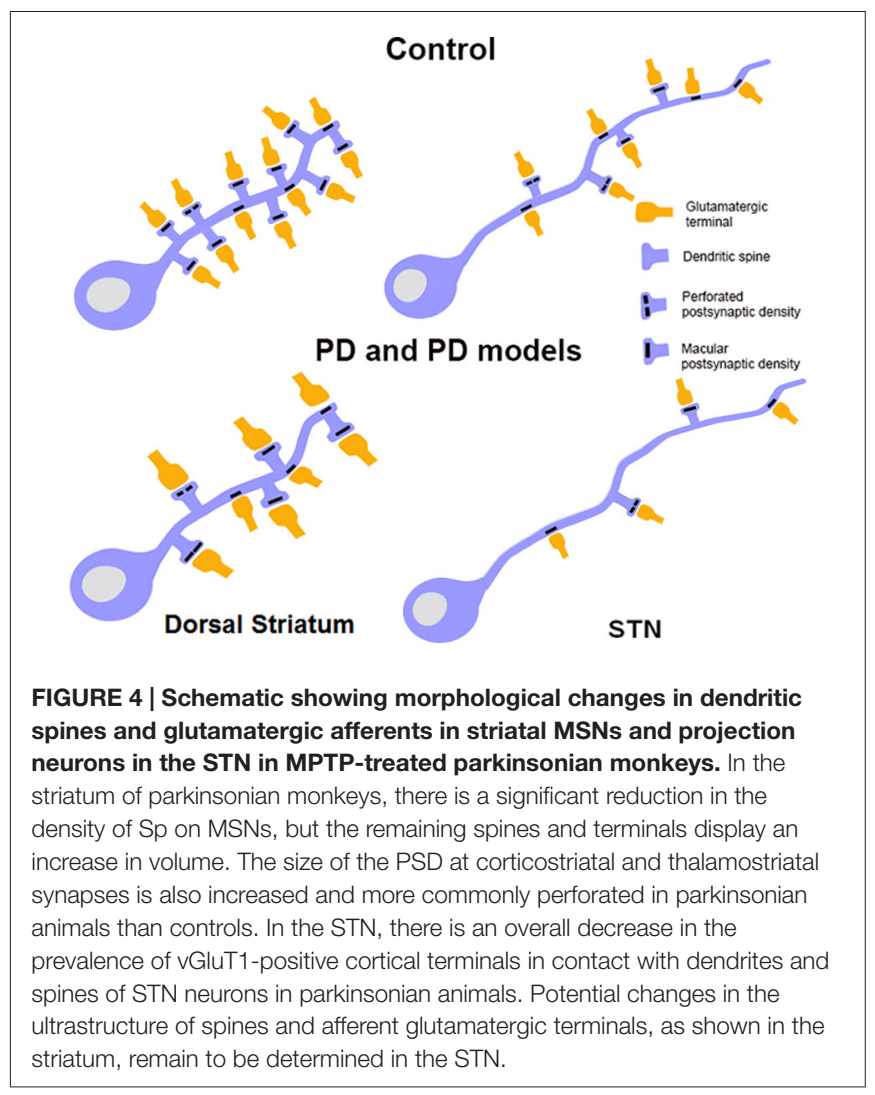

Because of its role in the regulation of neurite length and branching, LRRK2 mutation in PD may contribute to striatal spine pathology (MacLeod et al., 2006; Parisiadou et al., 2009; Lee et al., 2010).

\section{Changes in the Morphology of Astrocytes Associated with Glutamatergic Synapses in the Striatum of MPTP-Treated Monkeys}

Data from our laboratory showed that in addition to the structural remodeling of the pre-synaptic terminals and postsynaptic spines at cortical and thalamic glutamatergic synapses (Villalba and Smith, 2010, 2011a, 2013), there is a significant growth in the extent of glial coverage of striatal glutamatergic synapses in parkinsonian monkeys (Villalba and Smith, 2011b; Figure 2). Perisynaptic astrocytes exhibit an interdigitated finger-like morphology in control animals (Figure 2A), while there is an expansion of astrocytic processes to cover a larger extent of the perimeter of axo-spinous complexes after MPTP-treatment (Figure 2). In MPTP-treated monkeys, the appositions between the axo-spinous complex and the astroglial processes are much tighter and continuous than in controls (Figures 2E,F). These differences between the normal and MPTP conditions were seen for both vGluT1- and vGluT2positive glutamatergic synapses (Villalba and Smith, 2011b; Figures 2G,H).

A recent comparative study using $3 \mathrm{D}$ reconstruction in four animal models of $\mathrm{PD}$, as well as in human $\mathrm{PD}$, have shown 
that in response to DA denervation, astrocytes in both the striatum and GP occupy a larger striatal volume (Charron et al., 2014). This increase in striatal volume occupied by astrocytes in parkinsonism is due to an enlargement of astrocyte cell body and processes reorganization at the level of asymmetric synapses (Charron et al., 2014), but also to an increase in the number of astrocytes, a change known as reactive gliosis (Dervan et al., 2004; Henning et al., 2008; Charron et al., 2014). These morphological and ultrastructural changes in the perisynaptic astrocytes might underlie an active participation of glial processes in structural plasticity in the striatum, as previously shown in the hypothalamus (Theodosis et al., 2008) and hippocampus (Ventura and Harris, 1999; Witcher et al., 2007, 2010), suggesting that both glial and neuronal elements of axo-spinous glutamatergic synapses in the primate striatum are endowed with a high level of structural and functional plasticity. It is likely that such a synaptic arrangement is not homogeneous across all excitatory synapses (Ventura and Harris, 1999; Witcher et al., 2007, 2010), suggesting that some glutamatergic synapses may be more leaky and prone to spill over glutamate in the extracellular medium to activate extrasynaptic glutamate receptors than others.

These modifications in astrocytes morphology and in their spatial relationships with glutamatergic synapses in PD models, together with the different molecular mechanisms by which astrocytes respond to changes in neuronal activity, suggest that pathological changes in striatal astrocytes might play a key role in triggering and/or contributing to the morphological and functional changes in striatal network plasticity in parkinsonism (Villalba and Smith, 2011b). A better understanding of glianeuronal communication in normal and pathological conditions might help to develop new PD neurotherapeutic strategies.

\section{Breakdown of the Corticosubthalamic Projection in Parkinsonism}

The striatum and the STN are the main entry points for cortical information to the BG. Glutamatergic inputs to the STN originate from the cerebral cortex (Monakow et al., 1978; Nambu et al., 1996; Haynes and Haber, 2013), the thalamus (Sadikot et al., 1992), the brainstem PPN (Lavoie and Parent, 1994) and local axon collaterals of STN neurons (Kita et al., 1983; Kita and Kita, 2012). The parkinsonian state is associated with ultrastructural remodeling of synaptic connections which may contribute to activity changes in the BG. So far, such changes have been documented for the corticostriatal, thalamostriatal and pallidosubthalamic projections (Ingham et al., 1989; Meshul et al., 2000; Villalba et al., 2009; Villalba and Smith, 2011a, 2013; Fan et al., 2012). In line with evidence that the activity of the hyperdirect corticosubthalamic projection is altered in $\mathrm{PD}$ (Mathai and Smith, 2011; Yamawaki et al., 2012; Shimamoto et al., 2013; de Hemptinne et al., 2013; Delaville et al., 2015), we found a significant breakdown of the corticosubthalamic projection, characterized by a profound loss of vGluT1-positive terminals in the STN of parkinsonian monkeys (Mathai et al., 2015; Figures 3, 4).
However, the functional impact of this pathology on the corticosubthalamic transmission and the downstream BGthalamocortical circuitry remains to be clarified (Mathai et al., 2015). As shown in the striatum, possible homeostatic (or pathologic) changes in the strength and connectivity of remaining glutamatergic and GABAergic terminals in the STN might be induced (Ingham et al., 1989; Meshul et al., 2000; Smith et al., 2009b; Villalba and Smith, 2011a,b, 2013; Fieblinger et al., 2014a; Mathai et al., 2015). The known increase in the baseline (Bergman et al., 1994), and the greater degree of synchrony of STN neurons with cortical activity in PD are, indeed, in line with aberrant changes in corticosubthalamic transmission in the PD state (Williams et al., 2002, 2003, 2005; Moran et al., 2008; Gatev and Wichmann, 2009; Moshel et al., 2013; Shimamoto et al., 2013; Devergnas et al., 2014).

Thus, together with evidence for significant synaptic remodeling and altered glutamatergic transmission of the corticostriatal system in PD (Raju et al., 2008; Villalba and Smith, 2013; Fieblinger et al., 2014a), these findings suggest significant changes in the integration, processing and transmission of extrinsic cortical information to the BG in PD.

\section{Concluding Remarks}

For the past 25 years, it has been well recognized that degeneration of the nigrostriatal DA system induces loss of spines and complex plastic changes in the anatomical and functional organization of glutamatergic synapses in the mammalian striatum (Figure 4; for a review, see Villalba and Smith, 2013). The loss of spines has been demonstrated in various animal models and confirmed in PD patients. It has also been shown that the extent of spine loss in the striatum is tightly correlated with the degree of striatal DA denervation, but not with the severity of parkinsonian motor features, at least in MPTPtreated monkeys (Zaja-Milatovic et al., 2005; Smith and Villalba, 2008; Smith et al., 2009b; Villalba et al., 2009). Controversies remain as to whether direct or indirect pathway neurons are preferentially affected by this spine pathology. The animal species and the toxin being used, the chronic vs. acute regimen of intoxication and the time points at which observations are being made post-lesion likely contribute to the variability of results obtained in recent years (Ingham et al., 1989, 1998; Stephens et al., 2005; Zaja-Milatovic et al., 2005; Day et al., 2006; Scholz et al., 2008; Villalba et al., 2009; Suárez et al., 2014; Toy et al., 2014). Although indirect pathway neurons appear to be more sensitive than direct pathway neurons at early time points after DA depletion induced by 6-OHDA or reversible DA depleting agent like reserpine (Day et al., 2006; Fieblinger et al., 2014a), chronic MPTP toxicity in non-human primates and mice models of PD induces more widespread pathological effects upon both populations of striatofugal neurons (Villalba et al., 2009; Toy et al., 2014). In addition to spine loss, it has become clear that striatal MSNs also undergo a significant reduction in the length and number of dendritic branches in rodent models of $\mathrm{PD}$, and that such changes affect invariably both populations of striatofugal cells (Fieblinger et al., 2014a). 
The impact of striatal spine loss on the anatomical and functional connectivity of cortical and thalamic glutamatergic afferents has also generated significant interest in recent years, but significant issues remain to be addressed. Although authors agree that striatal spine loss is associated with a decrease in the number of total striatal glutamatergic synapses in the striatum, controversy remains as to whether these are accounted for by the loss of cortical over thalamic synapses (Raju et al., 2008; Villalba et al., 2013; Zhang et al., 2013; Fieblinger et al., 2014a). In acute, 6-OHDA-treated animals, vGluT1-positive corticostriatal terminals are selectively affected, without any impact on thalamostriatal vGluT2-positive boutons (Zhang et al., 2013; Fieblinger et al., 2014a), while the total number of vGluT1-immunoreactive boutons and amount of vGluT1 protein expression in the striatum is not significantly affected in chronically MPTP-treated parkinsonian monkeys and PD patients (Kashani et al., 2007; Raju et al., 2008; Villalba et al., 2013). In regards to the impact of spine loss on the prevalence of thalamic terminals and synaptic organization of the thalamostriatal system, the situation remains unclear, and also appears to be affected by the animal model being used (Kashani et al., 2007; Raju et al., 2008; Villalba et al., 2013; Zhang et al., 2013; Fieblinger et al., 2014a).

The concerns raised in this review about the animal model being used to address issues related to glutamatergic plasticity in $\mathrm{PD}$ is particularly important in the case of the thalamostriatal system because of the differential extent of CM/Pf (or Pf in rodents) cell loss in various models of PD (Freyaldenhoven et al., 1997; Ghorayeb et al., 2002a; Henderson et al., 2005; Aymerich et al., 2006; Sedaghat et al., 2009; Kusnoor et al., 2012; Smith et al., 2014a,b; Villalba et al., 2014). The lack of information about CM/Pf cell loss in some rodent models used in previous studies of striatal synaptic plasticity is a major limiting factor that complicates the use of this model to assess neuroplastic properties of striatal neurons and glutamatergic afferents in relation to $\mathrm{PD}$. Because $\mathrm{CM} / \mathrm{Pf}$ neuronal loss is a key pathological feature of PD (Henderson et al., 2000a,b; Smith et al., 2014a; Villalba et al., 2014), combined with the fact that the CM/Pf is

\section{References}

Alexander, G. E., DeLong, M. R., and Strick, P. L. (1986). Parallel organization of functionally segregated circuits linking basal ganglia and cortex. Annu. Rev. Neurosci. 9, 357-381. doi: 10.1146/annurev.neuro. 9.1.357

Antal, M., Beneduce, B. M., and Regehr, W. G. (2014). The substantia nigra conveys target-dependent excitatory and inhibitory outputs from the basal ganglia to the thalamus. J. Neurosci. 34, 8032-8042. doi: 10.1523/JNEUROSCI. 0236-14.2014

Arbuthnott, G. W., and Wickens, J. (2007). Space, time and dopamine. Trends Neurosci. 30, 62-69. doi: 10.1016/j.tins.2006.12.003

Arbuthnott, G. W., Ingham, C. A., and Wickens, J. R. (2000). Dopamine and synaptic plasticity in the neostriatum. J. Anat. 196, 587-596. doi: 10.1046/ j.1469-7580.2000.19640587.x

Aymerich, M. S., Barroso-Chinea, P., Pérez-Manso, M., Muñoz-Patiño, A. M., Moreno-Igoa, M., González-Hernández, T., et al. (2006). Consequences of unilateral nigrostriatal denervation on the thalamostriatal pathway in rats. Eur. J. Neurosci. 23, 2099-2108. doi: 10.1111/j.1460-9568.2006.04741.x the main source of thalamic inputs to the striatum, we believe that studies of striatal glutamatergic systems plasticity must be achieved in animal models that display thalamic pathology (Toy et al., 2014; Villalba et al., 2014).

Another interesting issue that has been put forward in recent years in regards to striatal spine loss in PD is the fact that LDOPA can restore the loss of spines on subsets (mainly D2R indirect pathway neurons) of striatal neurons in 6-OHDAtreated rats and mice. However, the chronic use of L-DOPA and the subsequent development of LID in this model is linked with the development of aberrant and excessive corticostriatal axo-dendritic and axo-spinous synapses (Zhang et al., 2013). It is unclear as to whether this pathological plasticity of the corticostriatal projection is also seen in other animal models of LID or in dyskinetic patients.

Although the striatum remains the BG structure that received most attention in studies of synaptic plasticity, recent evidence indicates that afferents to the STN are also morphologically and functionally disrupted in PD models. In MPTP-treated monkeys, a significant loss of vGluT1-containing cortical terminals has been reported, suggesting a partial degeneration of the hyperdirect corticosubthalamic pathway (Mathai et al., 2015). On the other hand, GABAergic GPe terminals also undergo major plastic changes that result in an increased strength of the pallidosubthalamic system in rodent models of PD (Fan et al., 2012). Ongoing studies are in progress to better understand the underlying mechanisms and the functional consequences of these plastic changes on the transmission, integration and processing of extrinsic information by STN neurons in PD.

\section{Acknowledgments}

The authors thank the Yerkes Center Animal Resources Division for help with the care of MPTP-treated monkeys. Jean-Francois Pare and Susan Jenkins are also thanked for technical assistance. This work was supported by the-NIH grants R01NS083386, R01NS037948, the Udall Center grant P50NS071669-01 and the Yerkes Primate Center base grant P51-OD011132.

Bergman, H., Wichmann, T., Karmon, B., and DeLong, M. R. (1994). The primate subthalamic nucleus. II. Neuronal activity in the MPTP model of parkinsonism. J. Neurophysiol. 72, 507-520.

Bernácer, J., Prensa, L., and Giménez-Amaya, J. M. (2005). Morphological features, distribution and compartmental organization of the nicotinamide adenine dinucleotide phosphate reduced-diaphorase interneurons in the human striatum. J. Comp. Neurol. 489, 311-327. doi: 10.1002/cne.20616

Bernácer, J., Prensa, L., and Giménez-Amaya, J. M. (2007). Cholinergic interneurons are differentially distributed in the human striatum. PLoS One 2:e1174. doi: 10.1371/journal.pone.0001174

Bernácer, J., Prensa, L., and Giménez-Amaya, J. M. (2012). Distribution of GABAergic interneurons and dopaminergic cells in the functional territories of the human striatum. PLoS One 7:e30504. doi: 10.1371/journal.pone. 0030504

Berns, G. S., and Sejnowski, T. J. (1998). A computational model of how the basal ganglia produce sequences. J. Cogn. Neurosci. 10, 108-121. doi: 10. $1162 / 089892998563815$

Bérubé-Carrière, N., Riad, M., Dal Bo, G., Lévesque, D., Trudeau, L. E., and Descarries, L. (2009). The dual dopamine-glutamate phenotype of growing 
mesencephalic neurons regresses in mature rat brain. J. Comp. Neurol. 517, 873-891. doi: 10.1002/cne.22194

Betarbet, R., Turner, R., Chockkan, V., DeLong, M. R., Allers, K. A., Walters, J., et al. (1997). Dopaminergic neurons intrinsic to the primate striatum. J. Neurosci. 17, 6761-6768.

Bevan, M. D., Francis, C. M., and Bolam, J. P. (1995). The glutamate-enriched cortical and thalamic input to neurons in the subthalamic nucleus of the rat: convergence with GABA-positive terminals. J. Comp. Neurol. 361, 491-511. doi: $10.1002 / \mathrm{cne} .903610312$

Bolam, J. P., and Pissadaki, E. K. (2012). Living on the edge with too many mouths to feed: why dopamine neurons die. Mov. Disord. 27, 1478-1483. doi: 10. $1002 / \mathrm{mds} .25135$

Bourne, J. N., and Harris, K. M. (2008). Balancing structure and function at hippocampal dendritic spines. Annu. Rev. Neurosci. 31, 47-67. doi: 10. 1146/annurev.neuro.31.060407.125646

Broadbelt, K. G., Paterson, D. S., Rivera, K. D., Trachtenberg, F. L., and Kinney, H. C. (2010). Neuroanatomic relationships between the GABAergic and serotonergic systems in the developing human medulla. Auton. Neurosci. 154, 30-34. doi: 10.1016/j.autneu.2009.10.002

Calabresi, P., Picconi, B., Tozzi, A., and Di Filippo, M. (2007). Dopamine-mediated regulation of corticostriatal synaptic plasticity. Trends Neurosci. 30, 211-219. doi: 10.1016/j.tins.2007.03.001

Carpenter, M. B., and Sutin, J. (1983). Human Neuroanatomy. 8th Edn Baltimore, MD, USA: Williams and Wilkins. 872.

Centonze, D., Grande, C., Usiello, A., Gubellini, P., Erbs, E., Martin, A. B., et al. (2003). Receptor subtypes involved in the presynaptic and postsynaptic actions of dopamine on striatal interneurons. J. Neurosci. 23, 6245-6254.

Charron, G., Doudnikoff, E., Canron, M. H., Li, Q., Véga, C., Marais, S., et al. (2014). Astrocytosis in parkinsonism: considering tripartite striatal synapses in physiopathology? Front. Aging Neurosci. 6:258. doi: 10.3389/fnagi.2014.00258

Chen, Y., Dubé, C. M., Rice, C. J., and Baram, T. Z. (2008). Rapid loss of dendritic spines after stress involves derangement of spine dynamics by corticotropinreleasing hormone. J. Neurosci. 28, 2903-2911. doi: 10.1523/JNEUROSCI.022508.2008

Chuhma, N., Zhang, H., Masson, J., Zhuang, X., Sulzer, D., Hen, R., et al. (2004). Dopamine neurons mediate a fast excitatory signal via their glutamatergic synapses. J. Neurosci. 24, 972-981. doi: 10.1523/jneurosci.4317-03.2004

Costa, R. M. (2007). Plastic corticostriatal circuits for action learning: what's dopamine got to do with it? Ann. N Y Acad. Sci. 1104, 172-192. doi: 10. 1196/annals.1390.015

Cragg, S. J., and Rice, M. E. (2004). DAncing past the DAT at a DA synapse. Trends Neurosci. 27, 270-277. doi: 10.1016/j.tins.2004.03.011

Day, M., Wang, Z., Ding, J., An, X., Ingham, C. A., Shering, A. F., et al. (2006). Selective elimination of glutamatergic synapses on striatopallidal neurons in Parkinson disease models. Nat. Neurosci. 9, 251-259. doi: 10.1038/nn1632

Day, M., Wokosin, D., Plotkin, J. L., Tian, X., and Surmeier, D. J. (2008). Differential excitability and modulation of striatal medium spiny neuron dendrites. J. Neurosci. 28, 11603-11614. doi: 10.1523/JNEUROSCI.1840-08. 2008

de Hemptinne, C., Ryapolova-Webb, E. S., Air, E. L., Garcia, P. A., Miller, K. J., Ojemann, J. G., et al. (2013). Exaggerated phase-amplitude coupling in the primary motor cortex in Parkinson disease. Proc. Natl. Acad. Sci. U S A 110, 4780-4785. doi: 10.1073/pnas.1214546110

Delaville, C., McCoy, A. J., Gerber, C. M., Cruz, A. V., and Walters, J. R. (2015). Subthalamic nucleus activity in the awake hemiparkinsonian rat: relationships with motor and cognitive networks. J. Neurosci. 35, 6918-6930. doi: 10. 1523/JNEUROSCI.0587-15.2015

Delle Donne, K. T., Sesack, S. R., and Pickel, V. M. (1996). Ultrastructural immunocytochemical localization of neurotensin and the dopamine D2 receptor in the rat nucleus accumbens. J. Comp. Neurol. 371, 552-566. doi: 10. 1002/(sici)1096-9861(19960805)371:4<552::aid-cne5>3.0.co;2-3

Delle Donne, K. T., Sesack, S. R., and Pickel, V. M. (1997). Ultrastructural immunocytochemical localization of the dopamine D2 receptor within GABAergic neurons of the rat striatum. Brain Res. 746, 239-255. doi: 10. 1016/s0006-8993(96)01226-7

DeLong, M., and Wichmann, T. (2010). Changing views of basal ganglia circuits and circuit disorders. Clin. EEG Neurosci. 41, 61-67. doi: 10. $1177 / 155005941004100204$
Dervan, A. G., Meshul, C. K., Beales, M., McBean, G. J., Moore, C., Totterdell, S., et al. (2004). Astroglial plasticity and glutamate function in a chronic mouse model of Parkinson's disease. Exp. Neurol. 190, 145-156. doi: 10.1016/ j.expneurol.2004.07.004

Descarries, L., Bérubé-Carrière, N., Riad, M., Bo, G. D., Mendez, J. A., and Trudeau, L. E. (2008). Glutamate in dopamine neurons: synaptic versus diffuse transmission. Brain Res. Rev. 58, 290-302. doi: 10.1016/j.brainresrev.2007. 10.005

Deutch, A. Y., Colbran, R. J., and Winder, D. J. (2007). Striatal plasticity and medium spiny neuron dendritic remodeling in parkinsonism. Parkinsonism Relat. Disord. 13(Suppl. 3), S251-S258. doi: 10.1016/s1353-8020(08) 70012-9

Devergnas, A., Pittard, D., Bliwise, D., and Wichmann, T. (2014). Relationship between oscillatory activity in the cortico-basal ganglia network and parkinsonism in MPTP-treated monkeys. Neurobiol. Dis. 68, 156-166. doi: 10. 1016/j.nbd.2014.04.004

Dodson, P. D., Larvin, J. T., Duffell, J. M., Garas, F. N., Doig, N. M., Kessaris, N., et al. (2015). Distinct developmental origins manifest in the specialized encoding of movement by adult neurons of the external globus pallidus. Neuron 86, 501-513. doi: 10.1016/j.neuron.2015.03.007

Ellender, T. J., Huerta-Ocampo, I., Deisseroth, K., Capogna, M., and Bolam, J. P. (2011). Differential modulation of excitatory and inhibitory striatal synaptic transmission by histamine. J. Neurosci. 31, 15340-15351. doi: 10 1523/JNEUROSCI.3144-11.2011

Fan, K. Y., Baufreton, J., Surmeier, D. J., Chan, C. S., and Bevan, M. D. (2012). Proliferation of external globus pallidus-subthalamic nucleus synapses following degeneration of midbrain dopamine neurons. J. Neurosci. 32, 13718-13728. doi: 10.1523/JNEUROSCI.5750-11.2012

Fieblinger, T., and Cenci, M. A. (2015). Zooming in on the small: the plasticity of striatal dendritic spines in L-DOPA-induced dyskinesia. Mov. Disord. 30 , 484-493. doi: 10.1002/mds.26139

Fieblinger, T., Graves, S. M., Sebel, L. E., Alcacer, C., Plotkin, J. L., Gertler, T. S., et al. (2014a). Cell type-specific plasticity of striatal projection neurons in parkinsonism and L-DOPA-induced dyskinesia. Nat. Commun. 5:5316. doi: 10. 1038/ncomms6316

Fieblinger, T., Sebastianutto, I., Alcacer, C., Bimpisidis, Z., Maslava, N., Sandberg, S., et al. (2014b). Mechanisms of dopamine D1 receptor-mediated ERK1/2 activation in the parkinsonian striatum and their modulation by metabotropic glutamate receptor type 5. J. Neurosci. 34, 4728-4740. doi: 10 . 1523/JNEUROSCI.2702-13.2014

Fifková, E., Markham, J. A., and Delay, R. J. (1983). Calcium in the spine apparatus of dendritic spines in the dentate molecular layer. Brain Res. 266, 163-168. doi: 10.1016/0006-8993(83)91322-7

Francois, C., Yelnik, J., Percheron, G., and Tandé, D. (1994). Calbindin D-28k as a marker for the associative cortical territory of the striatum in macaque. Brain Res. 633, 331-336. doi: 10.1016/0006-8993(94)91557-1

Freund, T. F., Powell, J. F., and Smith, A. D. (1984). Tyrosine hydroxylaseimmunoreactive boutons in synaptic contact with identified striatonigral neurons, with particular reference to dendritic spines. Neuroscience 13, 1189-1215. doi: 10.1016/0306-4522(84)90294-x

Freyaldenhoven, T. E., Ali, S. F., and Schmued, L. C. (1997). Systemic administration of MPTP induces thalamic neuronal degeneration in mice. Brain Res. 759, 9-17. doi: 10.1016/s0006-8993(97)00045-0

Fudge, J. L., Kunishio, K., Walsh, P., Richard, C., and Haber, S. N. (2002). Amygdaloid projections to ventromedial striatal subterritories in the primate. Neuroscience 110, 257-275. doi: 10.1016/s0306-4522(01) 00546-2

Galvan, A., and Smith, Y. (2011). The primate thalamostriatal systems: anatomical organization, functional roles and possible involvement in Parkinson's disease. Basal Ganglia 1, 179-189. doi: 10.1016/j.baga.2011.09.001

García-Cabezas, M. A., Martínez-Sánchez, P., Sánchez-González, M. A., Garzón, M., and Cavada, C. (2009). Dopamine innervation in the thalamus: monkey versus rat. Cereb. Cortex 19, 424-434. doi: 10.1093/cercor/bhn093

Garcia-Rill, E., Simon, C., Smith, K., Kezunovic, N., and Hyde, J. (2011). The pedunculopontine tegmental nucleus: from basic neuroscience to neurosurgical applications: arousal from slices to humans: implications for DBS. J. Neural Transm. 118, 1397-1407. doi: 10.1007/s00702-0100500-x 
Gatev, P., and Wichmann, T. (2009). Interactions between cortical rhythms and spiking activity of single basal ganglia neurons in the normal and parkinsonian state. Cereb. Cortex 19, 1330-1344. doi: 10.1093/cercor/bhn171

Gerfen, C. R., Baimbridge, K. G., and Thibault, J. (1987). The neostriatal mosaic: III. Biochemical and developmental dissociation of patch-matrix mesostriatal systems. J. Neurosci. 7, 3935-3944.

Gerfen, C. R., Engber, T. M., Mahan, L. C., Susel, Z., Chase, T. N., Monsma, F. J., et al. (1990). D1 and D2 dopamine receptor-regulated gene expression of striatonigral and striatopallidal neurons. Science 250, 1429-1432. doi: 10. $1126 /$ science. 2147780

Gerfen, C. R., and Surmeier, D. J. (2011). Modulation of striatal projection systems by dopamine. Annu. Rev. Neurosci. 34, 441-466. doi: 10.1146/annurev-neuro061010-113641

Gertler, T. S., Chan, C. S., and Surmeier, D. J. (2008). Dichotomous anatomical properties of adult striatal medium spiny neurons. J. Neurosci. 28, 10814-10824. doi: 10.1523/jneurosci.2660-08.2008

Ghorayeb, I., Fernagut, P. O., Hervier, L., Labattu, B., Bioulac, B., and Tison, F. (2002a). A "single toxin-double lesion" rat model of striatonigral degeneration by intrastriatal 1-methyl-4-phenylpyridinium ion injection: a motor behavioral analysis. Neuroscience 115, 533-546. doi: 10.1016/s0306-4522(02)00401-3

Ghorayeb, I., Fernagut, P. O., Stefanova, N., Wenning, G. K., Bioulac, B., and Tison, F. (2002b). Dystonia is predictive of subsequent altered dopaminergic responsiveness in a chronic 1-methyl-4-phenyl-1,2,3,6-tetrahydropyridine+3nitropropionic acid model of striatonigral degeneration in monkeys. Neurosci. Lett. 335, 34-38. doi: 10.1016/s0304-3940(02)01137-0

Gonzales, K. K., and Smith, Y. (2015). Cholinergic interneurons in the dorsal and ventral striatum: anatomical and functional considerations in normal and diseased conditions. Ann. N Y Acad. Sci. doi: 10.1111/nyas.12762 [Epub ahead of print].

González-Hernández, T., Barroso-Chinea, P., Acevedo, A., Salido, E., and Rodríguez, M. (2001). Colocalization of tyrosine hydroxylase and GAD65 mRNA in mesostriatal neurons. Eur. J. Neurosci. 13, 57-67. doi: 10.1111/j.14609568.2001.01371.x

Groves, P. M., Linder, J. C., and Young, S. J. (1994). 5-hydroxydopamine-labeled dopaminergic axons: three-dimensional reconstructions of axons, synapses and postsynaptic targets in rat neostriatum. Neuroscience 58, 593-604. doi: 10 . 1016/0306-4522(94)90084-1

Gurney, K., Prescott, T. J., and Redgrave, P. (2001). A computational model of action selection in the basal ganglia. II. Analysis and simulation of behavior. Biol. Cybern. 84, 411-423. doi: 10.1007/pl00007985

Haber, S. N., Kunishio, K., Mizobuchi, M., and Lynd-Balta, E. (1995). The orbital and medial prefrontal circuit through the primate basal ganglia. J. Neurosci. 15, 4851-4867.

Haynes, W. I., and Haber, S. N. (2013). The organization of prefrontal-subthalamic inputs in primates provides an anatomical substrate for both functional specificity and integration: implications for basal ganglia models and deep brain stimulation. J. Neurosci. 33, 4804-4814. doi: 10.1523/jneurosci.4674-12.2013

Henderson, J. M., Carpenter, K., Cartwright, H., and Halliday, G. M. (2000a). Degeneration of the centre median-parafascicular complex in Parkinson's disease. Ann. Neurol. 47, 345-352. doi: 10.1002/15318249(200003)47:3<345::aid-ana10>3.3.co;2-m

Henderson, J. M., Carpenter, K., Cartwright, H., and Halliday, G. M. (2000b). Loss of thalamic intralaminar nuclei in progressive supranuclear palsy and Parkinson's disease: clinical and therapeutic implications. Brain 123, 1410-1421. doi: 10.1093/brain/123.7.1410

Henderson, J. M., Schleimer, S. B., Allbutt, H., Dabholkar, V., Abela, D., Jovic, J., et al. (2005). Behavioral effects of parafascicular thalamic lesions in an animal model of parkinsonism. Behav. Brain Res. 162, 222-232. doi: 10.1016/j.bbr. 2005.03.017

Henning, J., Strauss, U., Wree, A., Gimsa, J., Rolfs, A., Benecke, R., et al. (2008). Differential astroglial activation in 6-hydroxydopamine models of Parkinson's disease. Neurosci. Res. 62, 246-253. doi: 10.1016/j.neures.2008.09.001

Hersch, S. M., Ciliax, B. J., Gutekunst, C. A., Rees, H. D., Heilman, C. J., Yung, K. K., et al. (1995). Electron microscopic analysis of D1 and D2 dopamine receptor proteins in the dorsal striatum and their synaptic relationships with motor corticostriatal afferents. J. Neurosci. 15, 5222-5237.

Hikosaka, O. (2010). The habenula: from stress evasion to value-based decisionmaking. Nat. Rev. Neurosci. 11, 503-513. doi: 10.1038/nrn2866
Hirasawa, H., Puopolo, M., and Raviola, E. (2009). Extrasynaptic release of GABA by retinal dopaminergic neurons. J. Neurophysiol. 102, 146-158. doi: 10. 1152/jn.00130.2009

Hnasko, T. S., Chuhma, N., Zhang, H., Goh, G. Y., Sulzer, D., Palmiter, R. D., et al. (2010). Vesicular glutamate transport promotes dopamine storage and glutamate corelease in vivo. Neuron 65, 643-656. doi: 10.1016/j.neuron.2010. 02.012

Huerta-Ocampo, I., Mena-Segovia, J., and Bolam, J. P. (2014). Convergence of cortical and thalamic input to direct and indirect pathway medium spiny neurons in the striatum. Brain Struct. Funct. 219, 1787-1800. doi: 10 1007/s00429-013-0601-z

Iijima, K. (1993). Chemocytoarchitecture of the rat locus ceruleus. Histol. Histopathol. 8, 581-591.

Ingham, C. A., Hood, S. H., and Arbuthnott, G. W. (1989). Spine density on neostriatal neurones changes with 6-hydroxydopamine lesions and with age. Brain Res. 503, 334-338. doi: 10.1016/0006-8993(89)91686-7

Ingham, C. A., Hood, S. H., Taggart, P., and Arbuthnott, G. W. (1998). Plasticity of synapses in the rat neostriatum after unilateral lesion of the nigrostriatal dopaminergic pathway. J. Neurosci. 18, 4732-4743.

Kashani, A., Betancur, C., Giros, B., Hitsch, E., and El Mestikawy, S. (2007). Altered expression of vesicular glutamate transporters VGLUT1 and VGLUT2 in Parkinson disease. Neurobiol. Aging 28, 568-578. doi: 10.1016/ j.neurobiolaging.2006.02.010

Kawaguchi, Y., Wilson, C. J., Augood, S. J., and Emson, P. C. (1995). Striatal interneurones: chemical, physiological and morphological characterization. Trends Neurosci. 18, 527-535. doi: 10.1016/0166-2236(95) 98374-8

Kawaguchi, Y., Wilson, C. J., and Emson, P. C. (1990). Projection subtypes of rat neostriatal matrix cells revealed by intracellular injection of biocytin. $J$. Neurosci. 10, 3421-3438.

Kemp, J. M., and Powell, T. P. (1971a). The site of termination of afferent fibres in the caudate nucleus. Philos. Trans. R. Soc. Lond. B Biol. Sci. 262, 413-427. doi: 10.1098/rstb.1971.0104

Kemp, J. M., and Powell, T. P. (1971b). The synaptic organization of the caudate nucleus. Philos. Trans. R. Soc. Lond. B Biol. Sci. 262, 403-412. doi: 10.1098/rstb. 1971.0103

Kemp, J. M., and Powell, T. P. (1971c). The termination of fibres from the cerebral cortex and thalamus upon dendritic spines in the caudate nucleus: a study with the Golgi method. Philos. Trans. R. Soc. Lond. B Biol. Sci. 262, 429-439. doi: 10. 1098/rstb.1971.0105

Kita, H., Chang, H. T., and Kitai, S. T. (1983). The morphology of intracellularly labeled rat subthalamic neurons: a light microscopic analysis. J. Comp. Neurol. 215, 245-257. doi: 10.1002/cne.902150302

Kita, T., and Kita, H. (2012). The subthalamic nucleus is one of multiple innervation sites for long-range corticofugal axons: a single-axon tracing study in the rat. J. Neurosci. 32, 5990-5999. doi: 10.1523/jneurosci.5717-11. 2012

Kreitzer, A. C. (2009). Physiology and pharmacology of striatal neurons. Annu. Rev. Neurosci. 32, 127-147. doi: 10.1146/annurev.neuro.051508. 135422

Kreitzer, A. C., and Malenka, R. C. (2008). Striatal plasticity and basal ganglia circuit function. Neuron 60, 543-554. doi: 10.1016/j.neuron.2008. 11.005

Kusnoor, S. V., Bubser, M., and Deutch, A. Y. (2012). The effects of nigrostriatal dopamine depletion on the thalamic parafascicular nucleus. Brain Res. 1446, 46-55. doi: 10.1016/j.brainres.2012.01.040

Lanciego, J. L., Gonzalo, N., Castle, M., Sanchez-Escobar, C., Aymerich, M. S., and Obeso, J. A. (2004). Thalamic innervation of striatal and subthalamic neurons projecting to the rat entopeduncular nucleus. Eur. J. Neurosci. 19, 1267-1277. doi: 10.1111/j.1460-9568.2004.03244.x

Lanciego, J. L., Luquin, N., and Obeso, J. A. (2012). Functional neuroanatomy of the basal ganglia. Cold Spring Harb. Perspect. Med. 2:a009621. doi: 10. 1101/cshperspect.a009621

Landwehrmeyer, B., Mengod, G., and Palacios, J. M. (1993). Differential visualization of dopamine D2 and D3 receptor sites in rat brain. A comparative study using in situ hybridization histochemistry and ligand binding autoradiography. Eur. J. Neurosci. 5, 145-153. doi: 10.1111/j.14609568.1993.tb00480.x 
Lavoie, B., and Parent, A. (1994). Pedunculopontine nucleus in the squirrel monkey: cholinergic and glutamatergic projections to the substantia nigra. $J$. Comp. Neurol. 344, 232-241. doi: 10.1002/cne.903440205

Lavoie, B., Smith, Y., and Parent, A. (1989). Dopaminergic innervation of the basal ganglia in the squirrel monkey as revealed by tyrosine hydroxylase immunohistochemistry. J. Comp. Neurol. 289, 36-52. doi: 10.1002/cne. 902890104

Lee, H., Melrose, H. L., Yue, M., Pare, J. F., Farrer, M. J., and Smith, Y. (2010). Lrrk2 localization in the primate basal ganglia and thalamus: a light and electron microscopic analysis in monkeys. Exp. Neurol. 224, 438-447. doi: 10.1016/ j.expneurol.2010.05.004

Lei, W., Deng, Y., Liu, B., Mu, S., Guley, N. M., Wong, T., et al. (2013). Confocal laser scanning microscopy and ultrastructural study of VGLUT2 thalamic input to striatal projection neurons in rats. J. Comp. Neurol. 521, 1354-1377. doi: 10. $1002 /$ cne.23235

Lei, W., Jiao, Y., Del Mar, N., and Reiner, A. (2004). Evidence for differential cortical input to direct pathway versus indirect pathway striatal projection neurons in rats. J. Neurosci. 24, 8289-8299. doi: 10.1523/jneurosci.1990-04. 2004

Lynd-Balta, E., and Haber, S. N. (1994a). The organization of midbrain projections to the striatum in the primate: sensorimotor-related striatum versus ventral striatum. Neuroscience 59, 625-640. doi: 10.1016/0306-4522(94) 90182-1

Lynd-Balta, E., and Haber, S. N. (1994b). The organization of midbrain projections to the ventral striatum in the primate. Neuroscience 59, 609-623. doi: 10. 1016/0306-4522(94)90181-3

MacLeod, D., Dowman, J., Hammond, R., Leete, T., Inoue, K., and Abeliovich, A. (2006). The familial Parkinsonism gene LRRK2 regulates neurite process morphology. Neuron 52, 587-593. doi: 10.1016/j.neuron.2006.10.008

Maher, B. J., and Westbrook, G. L. (2008). Co-transmission of dopamine and GABA in periglomerular cells. J. Neurophysiol. 99, 1559-1564. doi: 10.1152/ in. 00636.2007

Mallet, N., Micklem, B. R., Henny, P., Brown, M. T., Williams, C., Bolam, J. P., et al. (2012). Dichotomous organization of the external globus pallidus. Neuron 74, 1075-1086. doi: 10.1016/j.neuron.2012.04.027

Mathai, A., Ma, Y., Paré, J. F., Villalba, R. M., Wichmann, T., and Smith, Y. (2015). Reduced cortical innervation of the subthalamic nucleus in MPTPtreated parkinsonian monkeys. Brain 138, 946-962. doi: 10.1093/brain/ awv018

Mathai, A., Pare, J. F., Jenkins, S., and Smith, Y. (2012). A vGluT1-positive projection to the primate globus pallidus: evidence for a cortico-pallidal system in primates? Soc. Neurosci. Abstr 790.06.

Mathai, A., and Smith, Y. (2011). The corticostriatal and corticosubthalamic pathways: two entries, one target. So what? Front. Syst. Neurosci. 5:64. doi: 10. 3389/fnsys.2011.00064

Matsuda, W., Furuta, T., Nakamura, K. C., Hioki, H., Fujiyama, F., and Arai, R. (2009). Single nigrostriatal dopaminergic neurons form widely spread and highly dense axonal arborizations in the neostriatum. J. Neurosci. 29, 444-453. doi: 10.1523/JNEUROSCI.4029-08.2009

Mazloom, M., and Smith, Y. (2006). Synaptic microcircuitry of tyrosine hydroxylase-containing neurons and terminals in the striatum of 1-methyl4-phenyl-1,2,3,6-tetrahydropyridine-treated monkeys. J. Comp. Neurol. 495, 453-469. doi: $10.1002 / \mathrm{cne} .20894$

McGeorge, A. J., and Faull, R. L. (1987). The organization and collateralization of corticostriate neurones in the motor and sensory cortex of the rat brain. Brain Res. 423, 318-324. doi: 10.1016/0006-8993(87) 90855-9

Mena-Segovia, J., Bolam, J. P., and Magill, P. J. (2004). Pedunculopontine nucleus and basal ganglia: distant relatives or part of the same family? Trends Neurosci. 27, 585-588. doi: 10.1016/j.tins.2004.07.009

Meshul, C. K., Cogen, J. P., Cheng, H. W., Moore, C., Krentz, L., and McNeill, T. H. (2000). Alterations in rat striatal glutamate synapses following a lesion of the cortico- and/or nigrostriatal pathway. Exp. Neurol. 165, 191-206. doi: 10. 1006/exnr.2000.7467

Milardi, D., Bramanti, P., Milazzo, C., Finocchio, G., Arrigo, A., Santoro, G., et al. (2015). Cortical and subcortical connections of the human claustrum revealed in vivo by constrained spherical deconvolution tractography. Cereb. Cortex 25 , 406-414. doi: 10.1093/cercor/bht231
Mink, J. W. (1996). The basal ganglia: focused selection and inhibition of competing motor programs. Prog. Neurobiol. 50, 381-425. doi: 10.1016/s03010082(96)00042-1

Monakow, K. H., Akert, K., and Künzle, H. (1978). Projections of the precentral motor cortex and other cortical areas of the frontal lobe to the subthalamic nucleus in the monkey. Exp. Brain Res. 33, 395-403. doi: 10.1007/ bf00235561

Morales, M., and Root, D. H. (2014). Glutamate neurons within the midbrain dopamine regions. Neuroscience 282, 60-68. doi: 10.1016/j.neuroscience.2014. 05.032

Moran, A., Bergman, H., Israel, Z., and Bar-Gad, I. (2008). Subthalamic nucleus functional organization revealed by parkinsonian neuronal oscillations and synchrony. Brain 131, 3395-3409. doi: 10.1093/brain/awn270

Moshel, S., Shamir, R. R., Raz, A., de Noriega, F. R., Eitan, R., Bergman, H., et al. (2013). Subthalamic nucleus long-range synchronization-an independent hallmark of human Parkinson's disease. Front. Syst. Neurosci. 7:79. doi: 10. 3389/fnsys.2013.00079

Moss, J., and Bolam, J. P. (2008). A dopaminergic axon lattice in the striatum and its relationship with cortical and thalamic terminals. J. Neurosci. 28 , 11221-11230. doi: 10.1523/JNEUROSCI.2780-08.2008

Naito, A., and Kita, H. (1994). The cortico-nigral projection in the rat: an anterograde tracing study with biotinylated dextran amine. Brain Res. 637, 317-322. doi: 10.1016/0006-8993(94)91252-1

Nambu, A., Takada, M., Inase, M., and Tokuno, H. (1996). Dual somatotopical representations in the primate subthalamic nucleus: evidence for ordered but reversed body-map transformations from the primary motor cortex and the supplementary motor area. J. Neurosci. 16, 2671-2683.

Nambu, A., Tokuno, H., Hamada, I., Kita, H., Imanishi, M., Akazawa, T., et al. (2000). Excitatory cortical inputs to pallidal neurons via the subthalamic nucleus in the monkey. J. Neurophysiol. 84, 289-300.

Nambu, A., Tokuno, H., and Takada, M. (2002). Functional significance of the cortico-subthalamo-pallidal 'hyperdirect' pathway. Neurosci. Res. 43, 111-117. doi: 10.1016/s0168-0102(02)00027-5

Neely, M. D., Schmidt, D. E., and Deutch, A. Y. (2007). Cortical regulation of dopamine depletion-induced dendritic spine loss in striatal medium spiny neurons. Neuroscience 149, 457-464. doi: 10.1016/j.neuroscience.2007.06.044

Nicola, S. M., Surmeier, J., and Malenka, R. C. (2000). Dopaminergic modulation of neuronal excitability in the striatum and nucleus accumbens. Annu. Rev. Neurosci. 23, 185-215. doi: 10.1146/annurev.neuro.23.1.185

Nishijima, H., Suzuki, S., Kon, T., Funamizu, Y., Ueno, T., Haga, R., et al. (2014). Morphologic changes of dendritic spines of striatal neurons in the levodopainduced dyskinesia model. Mov. Disord. 29, 336-343. doi: 10.1002/mds. 25826

Oertner, T. G., and Matus, A. (2005). Calcium regulation of actin dynamics in dendritic spines. Cell Calcium 37, 477-482. doi: 10.1016/j.ceca.2005.01.016

Oorschot, D. E. (1996). Total number of neurons in the neostriatal, pallidal, subthalamic and substantia nigral nuclei of the rat basal ganglia: a stereological study using the cavalieri and optical disector methods. J. Comp. Neurol. 366, 580-599. doi: 10.1002/(sici)1096-9861(19960318)366:4<580::aid-cne3>3. $0 . \operatorname{co} ; 2-0$

Pahapill, P. A., and Lozano, A. M. (2000). The pedunculopontine nucleus and Parkinson's disease. Brain 123, 1767-1783. doi: 10.1093/brain/123.9.1767

Paquet, M., and Smith, Y. (2003). Group I metabotropic glutamate receptors in the monkey striatum: subsynaptic association with glutamatergic and dopaminergic afferents. J. Neurosci. 23, 7659-7669.

Parent, A., and De Bellefeuille, L. (1982). Organization of efferent projections from the internal segment of globus pallidus in primate as revealed by fluorescence retrograde labeling method. Brain Res. 245, 201-213. doi: 10.1016/00068993(82)90802-2

Parent, A., and Hazrati, L. N. (1995). Functional anatomy of the basal ganglia. II. The place of subthalamic nucleus and external pallidum in basal ganglia circuitry. Brain Res. Brain Res. Rev. 20, 2091-2127. doi: 10.1016/01650173(94)00008-d

Parent, A., Mackey, A., Smith, Y., and Boucher, R. (1983). The output organization of the substantia nigra in primate as revealed by a retrograde double labeling method. Brain Res. Bull. 10, 529-537. doi: 10.1016/0361-9230(83)90151-x

Parisiadou, L., Xie, C., Cho, H. J., Lin, X., Gu, X. L., Long, C. X., et al. (2009). Phosphorylation of ezrin/radixin/moesin proteins by LRRK2 promotes the 
rearrangement of actin cytoskeleton in neuronal morphogenesis. J. Neurosci. 29, 13971-13980. doi: 10.1523/JNEUROSCI.3799-09.2009

Picconi, B., Piccoli, G., and Calabresi, P. (2012). Synaptic dysfunction in Parkinson's disease. Adv. Exp. Med. Biol. 970, 553-572. doi: 10.1007/978-37091-0932-8_24

Pissadaki, E. K., and Bolam, J. P. (2013). The energy cost of action potential propagation in dopamine neurons: clues to susceptibility in Parkinson's disease. Front. Comput. Neurosci. 7:13. doi: 10.3389/fncom.2013.00013

Plotkin, J. L., Shen, W., Rafalovich, I., Sebel, L. E., Day, M., Chan, C. S., et al. (2013). Regulation of dendritic calcium release in striatal spiny projection neurons. $J$. Neurophysiol. 110, 2325-2336. doi: 10.1152/jn.00422.2013

Prensa, L., and Parent, A. (2001). The nigrostriatal pathway in the rat: a singleaxon study of the relationship between dorsal and ventral tier nigral neurons and the striosome/matrix striatal compartments. J. Neurosci. 21, 7247-7260.

Pulipparacharuvil, S., Renthal, W., Hale, C. F., Taniguchi, M., Xiao, G., Kumar, A., et al. (2008). Cocaine regulates MEF2 to control synaptic and behavioral plasticity. Neuron 59, 621-633. doi: 10.1016/j.neuron.2008.06.020

Raju, D. V., Ahern, T. H., Shah, D. J., Wright, T. M., Standaert, D. G., Hall, R. A., et al. (2008). Differential synaptic plasticity of the corticostriatal and thalamostriatal systems in an MPTP-treated monkey model of parkinsonism. Eur. J. Neurosci. 27, 1647-1658. doi: 10.1111/j.1460-9568.2008. 06136.x

Reynolds, J. N., and Wickens, J. R. (2002). Dopamine-dependent plasticity of corticostriatal synapses. Neural Netw. 15, 507-521. doi: 10.1016/s08936080(02)00045-x

Rice, M. E., and Cragg, S. J. (2008). Dopamine spillover after quantal release: rethinking dopamine transmission in the nigrostriatal pathway. Brain Res. Rev. 58, 303-313. doi: 10.1016/j.brainresrev.2008.02.004

Rice, M. E., Patel, J. C., and Cragg, S. J. (2011). Dopamine release in the basal ganglia. Neuroscience 198, 112-137. doi: 10.1016/j.neuroscience.2011.08.066

Rivera, A., Cuéllar, B., Girón, F. J., Grandy, D. K., de la Calle, A., and Moratalla, R. (2002). Dopamine D4 receptors are heterogeneously distributed in the striosomes/matrix compartments of the striatum. J. Neurochem. 80, 219-229. doi: 10.1046/j.0022-3042.2001.00702.x

Rommelfanger, K. S., and Wichmann, T. (2010). Extrastriatal dopaminergic circuits of the basal ganglia. Front. Neuroanat. 4:139. doi: 10.3389/fnana.2010. 00139

Russchen, F. T., Baskst, I., Amaral, D. G., and Price, J. L. (1985). The amygdalostriatal projections in the monkey. An anterograde tracing study. Brain Res. 329, 241-257. doi: 10.1016/0006-8993(85)90530-x

Rye, D. B., Lee, H. J., Saper, C. B., and Wainer, B. H. (1988). Medullary and spinal efferents of the pedunculopontine tegmental nucleus and adjacent mesopontine tegmentum in the rat. J. Comp. Neurol. 269, 315-341. doi: 10. 1002/cne.902690302

Sabatini, B. L., Maravall, M., and Svoboda, K. (2001). Ca(2+) signaling in dendritic spines. Curr. Opin. Neurobiol. 11, 349-356. doi: 10.1016/S0959-4388(00) 00218-X

Sadikot, A. F., Parent, A., and Francois, C. (1992). Efferent connections of the centromedian and parafascicular thalamic nuclei in the squirrel monkey: a PHA-L study of subcortical projections. J. Comp. Neurol. 315, 137-159. doi: 10. 1002/cne.903150203

Sano, H., Chiken, S., Hikida, T., Kobayashi, K., and Nambu, A. (2013). Signals through the striatopallidal indirect pathway stop movements by phasic excitation in the substantia nigra. J. Neurosci. 33, 7583-7594. doi: 10. 1523/JNEUROSCI.4932-12.2013

Saunders, A., Oldenburg, I. A., Berezovskii, V. K., Johnson, C. A., Kingery, N. D., Elliott, H. L., et al. (2015). A direct GABAergic output from the basal ganglia to frontal cortex. Nature 521, 85-89. doi: 10.1038/nature14179

Scholz, B., Svensson, M., Alm, H., Sköld, K., Fälth, M., Kultima, K., et al. (2008). Striatal proteomic analysis suggests that first L-dopa dose equates to chronic exposure. PLoS One 3:e1589. doi: 10.1371/journal.pone.0001589

Sedaghat, K., Finkelstein, D. I., and Gundlach, A. L. (2009). Effect of unilateral lesion of the nigrostriatal dopamine pathway on survival and neurochemistry of parafascicular nucleus neurons in the rat-evaluation of time-course and LGR8 expression. Brain Res. 1271, 83-94. doi: 10.1016/j.brainres.2009.03.026

Segal, I., Korkotian, I., and Murphy, D. D. (2000). Dendritic spine formation and pruning: common cellular mechanisms? Trends Neurosci. 23, 53-57. doi: 10. 1016/s0166-2236(99)01499-x
Shen, W., Flajolet, M., Greengard, P., and Surmeier, D. J. (2008). Dichotomous dopaminergic control of striatal synaptic plasticity. Science 321, 848-851. doi: $10.1126 /$ science. 1160575

Shimamoto, S. A., Ryapolova-Webb, E. S., Ostrem, J. L., Galifianakis, N. B., Miller, K. J., and Starr, P. A. (2013). Subthalamic nucleus neurons are synchronized to primary motor cortex local field potentials in Parkinson's disease. J. Neurosci. 33, 7220-7233. doi: 10.1523/JNEUROSCI.4676-12.2013

Shink, E., Bevan, M. D., Bolam, J. P., and Smith, Y. (1996). The subthalamic nucleus and the external pallidum: two tightly interconnected structures that control the output of the basal ganglia in the monkey. Neuroscience 73 , 335-357. doi: 10.1016/0306-4522(96)00022-x

Sidibé, M., and Smith, Y. (1999). Thalamic inputs to striatal interneurons in monkeys: synaptic organization and co-localization of calcium binding proteins. Neuroscience 89, 1189-1208. doi: 10.1016/s0306-4522(98) 00367-4

Smith, A. D., and Bolam, J. P. (1990). The neural network of the basal ganglia as revealed by the study of synaptic connections of identified neurones. Trends Neurosci. 13, 259-265. doi: 10.1016/0166-2236(90)90106-k

Smith, Y., and Kieval, J. Z. (2000). Anatomy of the dopamine system in the basal ganglia. Trends Neurosci. 23, S28-S33. doi: 10.1016/s1471-1931(00) 00023-9

Smith, Y., and Parent, A. (1986). Differential connections of caudate nucleus and putamen in the squirrel monkey (Saimiri sciureus). Neuroscience 18, 347-371. doi: 10.1016/0306-4522(86)90159-4

Smith, Y., and Villalba, R. (2008). Striatal and extrastriatal dopamine in the basal ganglia: an overview of its anatomical organization in normal and Parkinsonian brains. Mov. Disord. 23(Suppl. 3), S534-S547. doi: 10.1002/mds.22027

Smith, Y., and Wichmann, T. (2015). The cortico-pallidal projection: an additional route for cortical regulation of the basal ganglia circuitry. Mov. Disord. 30, 293-295. doi: 10.1002/mds.26095

Smith, Y., Bennett, B. D., Bolam, J. P., Parent, A., and Sadikot, A. F. (1994). Synaptic relationships between dopaminergic afferents and cortical or thalamic input in the sensorimotor territory of the striatum in monkey. J. Comp. Neurol. 344, 1-19. doi: 10.1002/cne.903440102

Smith, Y., Bevan, M. D., Shink, E., and Bolam, J. P. (1998a). Microcircuitry of the direct and indirect pathways of the basal ganglia. Neuroscience 86, 353-387.

Smith, Y., Shink, E., and Sidibé, M. (1998b). Neuronal circuitry and synaptic connectivity of the basal ganglia. Neurosurg. Clin. N. Am. 9, 203-222.

Smith, Y., Galvan, A., Ellender, T. J., Doig, N., Villalba, R. M., Huerta-Ocampo, I., et al. (2014a). The thalamostriatal system in normal and diseased states. Front. Syst. Neurosci. 8:5. doi: 10.3389/fnsys.2014.00005

Smith, Y., Wichmann, T., and DeLong, M. R. (2014b). Corticostriatal and mesocortical dopamine systems: do species differences matter? Nat. Rev. Neurosci. 15:63. doi: 10.1038/nrn3469-c1

Smith, Y., Mathai, A., Pare, J.-F., and Moot, R. C. (2014c). A putative vGluT1positive glutamatergic cortico-pallidal projection: differential organization between the internal and external globus pallidus. Soc. Neurosci. Abstr 248.10.

Smith, Y., Raju, D. V., Pare, J. F., and Sidibe, M. (2004). The thalamostriatal system: a highly specific network of the basal ganglia circuitry. Trends Neurosci. 27, 520-527. doi: 10.1016/j.tins.2004.07.004

Smith, Y., Raju, D., Nanda, B., Pare, J. F., Galvan, A., and Wichmann, T. (2009a). The thalamostriatal systems: anatomical and functional organization in normal and parkinsonian states. Brain Res. Bull. 78, 60-68. doi: 10.1016/j.brainresbull. 2008.08.015

Smith, Y., Villalba, R. M., and Raju, D. V. (2009b). Striatal spine plasticity in Parkinson's disease: pathological or not? Parkinsonism Relat. Disord. 15(Suppl. 3), S156-S161. doi: 10.1016/S1353-8020(09)70805-3

Soderstrom, K. E., O’Malley, J. A., Levine, N. D., Sortwell, C. E., Collier, T. J., and Steece-Collier, K. (2010). Impact of dendritic spine preservation in medium spiny neurons on dopamine graft efficacy and the expression of dyskinesias in parkinsonian rats. Eur. J. Neurosci. 31, 478-490. doi: 10.1111/j.1460-9568.2010. 07077.x

Stephens, B., Mueller, A. J., Shering, A. F., Hood, S. H., Taggart, P., Arbuthnott, G. W., et al. (2005). Evidence of a breakdown of corticostriatal connections in Parkinson's disease. Neuroscience 132, 741-754. doi: 10.1016/j.neuroscience. 2005.01.007 
Suárez, L. M., Solís, O., Caramés, J. M., Taravini, I. R., Solís, J. M., Murer, M. G., et al. (2014). L-DOPA treatment selectively restores spine density in dopamine receptor D2-expressing projection neurons in dyskinetic mice. Biol. Psychiatry 75, 711-722. doi: 10.1016/j.biopsych.2013.05.006

Sulzer, D., Joyce, M. P., Lin, L., Geldwert, D., Haber, S. N., Hattori, T., et al. (1998). Dopamine neurons make glutamatergic synapses in vitro. J. Neurosci. 18, 4588-4602.

Surmeier, D. J., Ding, J., Day, M., Wang, Z., and Shen, W. (2007). D1 and D2 dopamine-receptor modulation of striatal glutamatergic signaling in striatal medium spiny neurons. Trends Neurosci. 30, 228-235. doi: 10.1016/j.tins.2007. 03.008

Surmeier, D. J., Guzman, J. N., Sanchez-Padilla, J., and Schumacker, P. T. (2011). The role of calcium and mitochondrial oxidant stress in the loss of substantia nigra pars compacta dopaminergic neurons in Parkinson's disease. Neuroscience 198, 221-231. doi: 10.1016/j.neuroscience.2011.08.045

Surmeier, D. J., and Kitai, S. T. (1993). D1 and D2 dopamine receptor modulation of sodium and potassium currents in rat neostriatal neurons. Prog. Brain Res. 99, 309-324. doi: 10.1016/s0079-6123(08)61354-0

Surmeier, D. J., and Schumacker, P. T. (2013). Calcium, bioenergetics and neuronal vulnerability in Parkinson's disease. J. Biol. Chem. 288, 10736-10741. doi: 10.1074/jbc.r112.410530

Surmeier, D. J., Shen, W., Day, M., Gertler, T., Chan, S., Tian, X., et al. (2010). The role of dopamine in modulating the structure and function of striatal circuits. Prog. Brain Res. 183, 149-167. doi: 10.1016/s0079-6123(10)83008-0

Surmeier, D. J., Song, W. J., and Yan, Z. (1996). Coordinated expression of dopamine receptors in neostriatal medium spiny neurons. J. Neurosci. 16, 6579-6591.

Tepper, J. M., and Bolam, J. P. (2004). Functional diversity and specificity of neostriatal interneurons. Curr. Opin. Neurobiol. 14, 685-692. doi: 10.1016/j. conb.2004.10.003

Tepper, J. M., Tecuapetla, F., Koós, T., and Ibáñez-Sandoval, O. (2010). Heterogeneity and diversity of striatal GABAergic interneurons. Front. Neuroanat. 4:150. doi: 10.3389/fnana.2010.00150

Theodosis, D. T., Poulain, D. A., and Oliet, S. H. (2008). Activity-dependent structural and functional plasticity of astrocyte-neuron interactions. Physiol. Rev. 88, 983-1008. doi: 10.1152/physrev.00036.2007

Tian, X., Kai, L., Hockberger, P. E., Wokosin, D. L., and Surmeier, D. J. (2010). MEF-2 regulates activity-dependent spine loss in striatopallidal medium spiny neurons. Mol. Cell. Neurosci. 44, 94-108. doi: 10.1016/j.mcn.2010.01.012

Toy, W. A., Petzinger, G. M., Leyshon, B. J., Akopian, G. K., Walsh, J. P., Hoffman, M. V., et al. (2014). Treadmill exercise reverses dendritic spine loss in direct and indirect striatal medium spiny neurons in the 1-methyl-4-phenyl-1,2,3,6tetrahydropyridine (MPTP) mouse model of Parkinson's disease. Neurobiol. Dis. 63, 201-209. doi: 10.1016/j.nbd.2013.11.017

Tritsch, N. X., Ding, J. B., and Sabatini, B. L. (2012). Dopaminergic neurons inhibit striatal output through non-canonical release of GABA. Nature 490, 262-266. doi: $10.1038 /$ nature 11466

Tritsch, N. X., Oh, W. J., Gu, C., and Sabatini, B. L. (2014). Midbrain dopamine neurons sustain inhibitory transmission using plasma membrane uptake of GABA, not synthesis. Elife 3:e01936. doi: 10.7554/eLife.01936

Trottier, S., Chotard, C., Traiffort, E., Unmehopa, U., Fisser, B., Swaab, D. F., et al. (2002). Co-localization of histamine with GABA but not with galanin in the human tuberomamillary nucleus. Brain Res. 939, 52-64. doi: 10.1016/s00068993(02)02546-5

Trudeau, L. E., Hnasko, T. S., Wallén-Mackenzie, A., Morales, M., Rayport, S., and Sulzer, D. (2014). The multilingual nature of dopamine neurons. Prog. Brain Res. 211, 141-164. doi: 10.1016/b978-0-444-63425-2.00006-4

Ventura, R., and Harris, K. M. (1999). Three-dimensional relationships between hippocampal synapses and astrocytes. J. Neurosci. 19, 6897-6906.

Villalba, R. M., Lee, H., and Smith, Y. (2009). Dopaminergic denervation and spine loss in the striatum of MPTP-treated monkeys. Exp. Neurol. 215, 220-227. doi: 10.1016/j.expneurol.2008.09.025

Villalba, R. M., and Smith, Y. (2010). Striatal spine plasticity in Parkinson's disease. Front. Neuroanat. 4:133. doi: 10.3389/fnana.2010.00133

Villalba, R. M., and Smith, Y. (2011a). Differential structural plasticity of corticostriatal and thalamostriatal axo-spinous synapses in MPTP-treated Parkinsonian monkeys. J. Comp. Neurol. 519, 989-1005. doi: 10.1002/cne. 22563
Villalba, R. M., and Smith, Y. (2011b). Neuroglial plasticity at striatal glutamatergic synapses in Parkinson's disease. Front. Syst. Neurosci. 5:68. doi: 10.3389/fnsys. 2011.00068

Villalba, R. M., and Smith, Y. (2013). Differential striatal spine pathology in Parkinson's disease and cocaine addiction: a key role of dopamine? Neuroscience 251, 2-20. doi: 10.1016/j.neuroscience.2013.07.011

Villalba, R. M., Wichmann, T., and Smith, Y. (2013). Preferential loss of thalamostriatal over corticostriatal glutamatergic synapses in MPTP-treated parkinsonian monkeys. Soc. Neurosci. Annu. Meet. Abstr. 240.02.

Villalba, R. M., Wichmann, T., and Smith, Y. (2014). Neuronal loss in the caudal intralaminar thalamic nuclei in a primate model of Parkinson's disease. Brain Struct. Funct. 219, 381-394. doi: 10.1007/s00429-013-0507-9

Wang, Z., Kai, L., Day, M., Ronesi, J., Yin, H. H., Ding, J., et al. (2006). Dopaminergic control of corticostriatal long-term synaptic depression in medium spiny neurons is mediated by cholinergic interneurons. Neuron 50 , 443-452. doi: 10.3410/f.1032530.374238

Wang, H., and Pickel, V. M. (2002). Dopamine D2 receptors are present in prefrontal cortical afferents and their targets in patches of the rat caudateputamen nucleus. J. Comp. Neurol. 442, 392-404. doi: 10.1002/cne.10086

Wickens, J. (2008). Toward an anatomy of disappointment: reward-related signals from the globus pallidus. Neuron 60, 530-531. doi: 10.1016/j.neuron.2008. 11.002

Wickens, J. R., Arbuthnott, G. W., and Shindou, T. (2007a). Simulation of GABA function in the basal ganglia: computational models of GABAergic mechanisms in basal ganglia function. Prog. Brain Res. 160, 313-329. doi: 10.1016/s00796123(06)60018-6

Wickens, J. R., Budd, C. S., Hyland, B. I., and Arbuthnott, G. W. (2007b). Striatal contributions to reward and decision making: making sense of regional variations in a reiterated processing matrix. Ann. N Y Acad. Sci. 1104, 192-212. doi: 10.1196/annals. 1390.016

Wickens, J. R., Horvitz, J. C., Costa, R. M., and Killcross, S. (2007c). Dopaminergic mechanisms in actions and habits. J. Neurosci. 27, 8181-8183. doi: 10 1523/jneurosci.1671-07.2007

Williams, D., Kühn, A., Kupsch, A., Tijssen, M., Van Bruggen, G., Speelman, H., et al. (2003). Behavioral cues are associated with modulations of synchronous oscillations in human subthalamic nucleus. Brain 126, 1975-1985. doi: 10. 1093/brain/awg194

Williams, D., Kühn, A., Kupsch, A., Tijssen, M., van Bruggen, G., Speelman, H., et al. (2005). The relationship between oscillatory activity and motor reaction time in the parkinsonian subthalamic nucleus. Eur. J. Neurosci. 21, 249-258. doi: 10.1111/j.1460-9568.2004.03817.x

Williams, D., Tijssen, M., Van Bruggen, G., Bosch, A., Insola, A., Di Lazzaro, V., et al. (2002). Dopamine-dependent changes in the functional connectivity between basal ganglia and cerebral cortex in humans. Brain 125, 1558-1569. doi: 10.1093/brain/awf156

Witcher, M. R., Kirov, S. A., and Harris, K. M. (2007). Plasticity of perisynaptic astroglia during synaptogenesis in the mature rat hippocampus. Glia 55, 13-23. doi: 10.1002/glia.20415

Witcher, M. R., Park, Y. D., Lee, M. R., Sharma, S., Harris, K. M., and Kirov, S. A. (2010). Three-dimensional relationships between perisynaptic astroglia and human hippocampal synapses. Glia 58, 572-587. doi: 10.1002/glia.20946

Wu, Y., Pearl, S. M., Zigmond, M. J., and Michael, A. C. (2000). Inhibitory glutamatergic regulation of evoked dopamine release in striatum. Neuroscience 96, 65-72. doi: 10.1016/s0306-4522(99)00539-4

Wurtz, R. H., and Hikosaka, O. (1986). Role of the basal ganglia in the initiation of saccadic eye movements. Prog. Brain Res. 64, 175-190. doi: 10.1016/s00796123(08)63412-3

Yamaguchi, T., Wang, H. L., and Morales, M. (2013). Glutamate neurons in the substantia nigra compacta and retrorubral field. Eur. J. Neurosci. 38, 3602-3610. doi: 10.1111/ejn.12359

Yamawaki, N., Magill, P. J., Woodhall, G. L., Hall, S. D., and Stanford, I. M. (2012). Frequency selectivity and dopamine-dependence of plasticity at glutamatergic synapses in the subthalamic nucleus. Neuroscience 203, 1-11. doi: 10.1016/j. neuroscience.2011.12.027

Yan, Z., Song, W. J., and Surmeier, J. (1997). D2 dopamine receptors reduce $\mathrm{N}$-type $\mathrm{Ca} 2+$ currents in rat neostriatal cholinergic interneurons through a membrane-delimited, protein-kinase-C-insensitive pathway. J. Neurophysiol. 77, 1003-1015. 
Yan, Z., and Surmeier, D. J. (1997). D5 dopamine receptors enhance Zn2+sensitive $\mathrm{GABA}(\mathrm{A})$ currents in striatal cholinergic interneurons through a PKA/PP1 cascade. Neuron 19, 1115-1126. doi: 10.1016/s0896-6273(00) 80402-X

Yung, K. K., Bolam, J. P., Smith, A. D., Hersch, S. M., Ciliax, B. J., and Levey, A. I. (1995). Immunocytochemical localization of D1 and D2 dopamine receptors in the basal ganglia of the rat: light and electron microscopy. Neuroscience 65, 709-730. doi: 10.1016/0306-4522(94)00536-e

Zaja-Milatovic, S., Milatovic, D., Schantz, A. M., Zhang, J., Montine, K. S., Samii, A., et al. (2005). Dendritic degeneration in neostriatal medium spiny neurons in parkinson disease. Neurology 64, 545-547. doi: 10.1212/01.wnl.0000150591. 33787.a4

Zhang, Y., Meredith, G. E., Mendoza-Elias, N., Rademacher, D. J., Tseng, K. Y., and Steece-Collier, K. (2013). Aberrant restoration of spines and their synapses in L-DOPA-induced dyskinesia: involvement of corticostriatal but but not thalamostriatal synapses. J. Neurosci. 33, 11655-11667. doi: 10. 1523/JNEUROSCI.0288-13.2013

Conflict of Interest Statement: The authors declare that the research was conducted in the absence of any commercial or financial relationships that could be construed as a potential conflict of interest.

Copyright (c) 2015 Villalba, Mathai and Smith. This is an open-access article distributed under the terms of the Creative Commons Attribution License (CC BY). The use, distribution and reproduction in other forums is permitted, provided the original author(s) or licensor are credited and that the original publication in this journal is cited, in accordance with accepted academic practice. No use, distribution or reproduction is permitted which does not comply with these terms. 